\title{
Phenolic Compounds as Arginase Inhibitors: New Insights Regarding Endothelial Dysfunction Treatment
}

Authors

Bruno Rodrigo Minozzo ${ }^{1}$, Daniel Fernandes ${ }^{2}$, Flávio Luís Beltrame ${ }^{1}$

Affiliations

1 Department of Pharmaceutical Sciences, State University of Ponta Grossa, Ponta Grossa, Paraná, Brazil

2 Department of Pharmacology, Federal University of Santa Catarina, Florianópolis, Santa Catarina, Brazil

Key words

vascular disease, endothelial nitric oxide synthase, nitric oxide, arginase, natural products, polyphenols

received August 5, 2017

revised December 9, 2017

accepted December 31, 2017

\section{Bibliography}

DOI https://doi.org/10.1055/s-0044-100398

Published online January 17, 2018 | Planta Med 2018; 84:

277-295 @ Georg Thieme Verlag KG Stuttgart · New York | ISSN 0032-0943

\section{Correspondence}

Professor Dr. Flávio Luís Beltrame

Department of Pharmaceutical Sciences, State University of Ponta Grossa, Room 23, Building M

4748 Carlos Cavalcanti Avenue, Uvaranas 84900-030,

Ponta Grossa, Paraná, Brazil

Phone: + 554232203782 , Fax: + 554232203102

flaviobeltra@gmail.com

\section{Correspondence}

Professor MSc. Bruno Rodrigo Minozzo

Department of Pharmaceutical Sciences, State University of Ponta Grossa, Room 23, Building M

4748 Carlos Cavalcanti Avenue, Uvaranas 84900-030, Ponta

Grossa, Paraná, Brazil

Phone: + 554232203782 , Fax: + 554232203102

brunominozzo@outlook.com

\section{ABSTRACT}

Endothelial dysfunction is characterised by the low bioavailability of nitric oxide with a relevant negative impact on the nitric oxide/cGMP pathway. The loss of nitric oxide/cGMP signaling may be caused by an increased arginase activity. Plant-derived substances, especially polyphenols, are compounds that have the potential to inhibit arginase activity and they may represent an attractive therapeutic option to combat clinical outcomes related to endothelial dysfunction. An extensive review was carried out using all available data published in English in the Pubmed database, and without restriction regarding the year of publication. Despite the increased number of new substances that have been tested as arginase inhibitors, it is rare to find a compound that satisfies all the toxicological criteria to be used in the development of a new drug. On the other hand, recent data have shown that substances from plants have great potential to be applied as arginase inhibitors, most of which are polyphenols. Of the relevant mechanisms in this process, the inhibition of arginase by natural products seems to act against endothelial dysfunction by reestablishing the vascular function and elevating nitric oxide levels (by increasing the amounts of substrate (L-arginine, and endothelial nitric oxide synthase activation and stabilisation) as well as decreasing the generation of reactive species (formed by uncoupledendothelial nitric oxide synthase). This review summarises several topics regarding arginase inhibition by natural substances as well as indicating this pathway as an emergent strategy to elevate nitric oxide levels in disorders involving endothelial dysfunction. In addition, some aspects regarding structural activity and future perspectives are discussed.

\section{Introduction}

Several diseases have been linked to the development of ED, such as atherosclerosis, hypercholesterolaemia, coronary disease, erectile dysfunction, asthma, renal failure, rheumatoid arthritis, periodontitis, psychiatric disorders, and cancer, as well as diseases with a high prevalence, such as diabetes (types 1 and 2) and SAH [1-9].
The preservation of the endothelium is fundamental in maintaining the physiology of the vascular system (in the regulation of its tonus, the development of immune, structural, and proliferative functions, and interaction with other cellular types) and also in the prevention of the development/aggravation of diseases [10-12]. 


\begin{tabular}{|c|c|}
\hline \multicolumn{2}{|c|}{ ABBREVIATIONS } \\
\hline $\mathrm{ABH}$ & amino-2-borono-6-hexanoic acid \\
\hline ADME & $\begin{array}{l}\text { absorption, distribution, metabolism, } \\
\text { and excretion }\end{array}$ \\
\hline All & angiotensin II \\
\hline ARG & arginase \\
\hline BAEC & bovine aortic endothelial cell arginase \\
\hline BEC & S-(2-boronoethyl)-I-cysteine \\
\hline b-ARG 1 & bovine liver arginase \\
\hline DFMO & alpha-difluoromethylornithine \\
\hline DM1 & type 1 diabetes mellitus \\
\hline ED & endothelial dysfunction \\
\hline EGFR & epidermal growth factor receptor \\
\hline $\mathrm{E}_{\max }$ & maximum effect \\
\hline eNOS & endothelial nitric oxide synthase \\
\hline HUVEC & human endothelial cell culture \\
\hline EDRF & endothelium-derived relaxing factor \\
\hline iNOS & inducible nitric oxide synthase \\
\hline LPS & lipopolysaccharide \\
\hline NOHA & $\mathrm{N} \omega$-hydroxy-L-arginine \\
\hline NO & nitric oxide \\
\hline NOS & nitric oxide synthase \\
\hline $\mathrm{O}_{2}^{\cdot-}$ & superoxide anion \\
\hline $\mathrm{OH} \cdot$ & hydroxyl \\
\hline $\mathrm{ONOO}^{-}$ & peroxynitrite \\
\hline oxLDL & oxidised low-density lipoprotein \\
\hline PG & piceatannol-3'-O- $\beta$-D-glucopyranoside \\
\hline ROS & reactive oxygen species \\
\hline SMC & smooth muscle cell \\
\hline SAH & systemic arterial hypertension \\
\hline TDF & $(2 S)-5,2^{\prime}, 5^{\prime}$-trihydroxy-7,8-dimethoxy flavanone \\
\hline THSG & $2,3,5,4^{\prime}$-tetrahydroxystilbene-2-O- $\beta$-D-glucoside \\
\hline
\end{tabular}

For example, in $\mathrm{SAH}$, vascular oxidative stress can precede the onset of elevated blood pressure, which, associated with conditions of hyperlipidaemia, can lead to the rapid proliferation of endothelial cells. However, the cellular division capacity is limited, which is caused by a cycle arrest of the endothelial cells. As a consequence, these senescent cells undergo morphological changes that are responsible for the increased production of reactive species, which leads to a decrease in the production of NO and increased sensitivity to apoptotic stimulus. Such events lead to progressive impairment in vascular responses, with an intensification of $\operatorname{ED}[10,13,14]$.

Thus, mechanisms such as oxidative stress, eNOS uncoupling, induction of endothelium-dependent contractile responses, and reduced endothelium-dependent hyperpolarisation can be related to a decrease in vascular response $[15,16]$. However, it is worth noting that although there are several factors involved in $\mathrm{ED}$, it is strongly marked by the low bioavailability of NO and, therefore, damage in the NO/cGMP pathway configures one of the most important causes of vascular impairment $[6,10,11]$.

In addition, NO is responsible for vascular smooth muscle relaxation, the inhibition of adhesion and aggregation of neutro- phils and platelets, participation in neurotransmission and memory processes, the immune system and gene regulation as well as cell cycle regulation and apoptosis. Due to these important effects, NO deficiency receives much attention and ED has already been mentioned in more than 20000 scientific studies, since both represent risk factors, especially in relation to cardiovascular diseases ( $\triangleright$ Fig. 1) $[6,17,18]$.

The best-characterised endothelium-derived relaxing factor (NO) is synthesised by NOS from the amino acid L-arginine, while another enzyme, L-arginine-urea hydrolase arginase, or simply ARG, is responsible for regulating the production of this biological mediator through substrate competition $[6,18]$.

A decrease in the formation of $\mathrm{NO}$ is a key point in the development of ED because there is competition for the common substrate, which raises interest in the modulating role of ARG in decreasing NO levels.

Such a modulating function may culminate in a number of vascular changes, which are characterised by impairment of vasodilatory response, increased inflammation, vascular remodelling (collagen deposition and smooth muscle tissue growth), altered platelet aggregation, and cellular apoptosis ( Fig. 2) [6, 25, 26].

It has been suggested that the inhibition of ARG activity may result in increased NOS substrate availability and, consequently, NO production. This hypothesis has been confirmed by in vitro and in vivo studies $[17,18,27-30]$.

In this context, research regarding the pharmacological inhibitors of ARG as options for the development of new molecules to treat metabolic, respiratory, infectious, and cardiovascular disorders is promising. However, few substances are available for this purpose, and problems related to the pharmacokinetic and toxicological factors of these substances have not yet been resolved [25-27, 31].

Recently, plant extracts and active plant metabolites have emerged as potential alternatives for therapeutic application in several diseases that affect humans. For example, the polyphenolic extract of Camellia sinensis (L.) Kuntze (Theaceae) was approved by the U.S. Food and Drug Administration in 2007 for the treatment of genital warts, and in 2012, ingenol mebutate, which is a tigliane diterpenoid, started to be used in the treatment of actinic keratosis [32,33]. Ethnopharmacological studies are currently being conducted in order to identify ARG inhibitory substances for future clinical use in relation to $E D$, specifically those related to cardiovascular alterations.

With regard to the latter point, special attention has been paid to substances belonging to the class of polyphenols [26, 29,3438]. Therefore, this article presents recent research regarding the search for new ARG inhibitors derived from medicinal plants with a potential therapeutic application in the fight against diseases related to the development of ED, as well as seeking to increase interest in the development of promising drugs in this field.

\section{Methods}

This systematic review of the literature was based on scientific material that has already been published in the English language, which was collected from the Pubmed (US National Library of Medicine - National Institutes of Health) database without restric- 


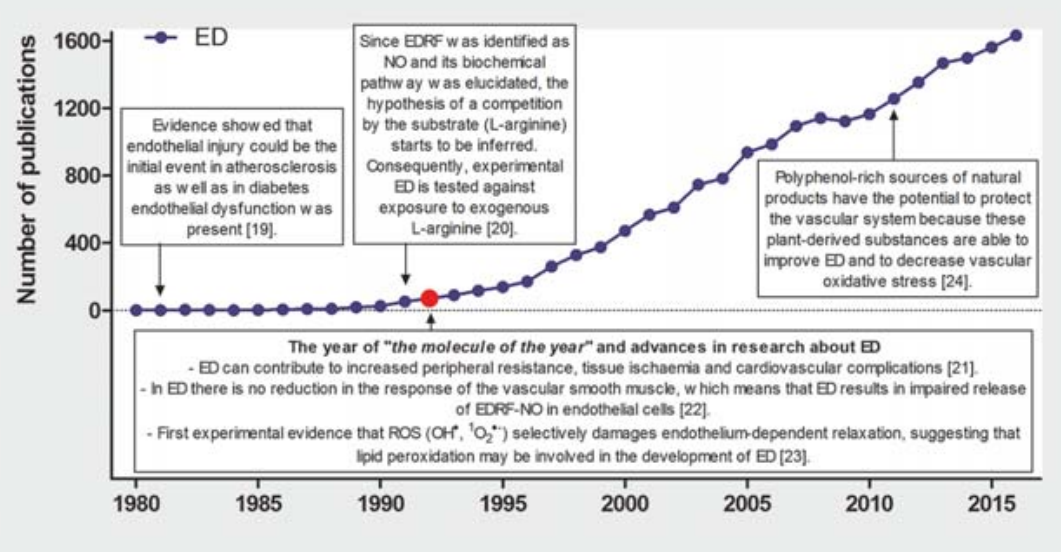

- Fig. 1 Number of scientific publications regarding ED, including its causes and consequences, as well as recent interest in the application of plant-derived substances in the prevention of its complications. The Pubmed database (December 2016) was used to obtain the data and "endothelial dysfunction" was applied as the search term. EDRF: endothelium-derived relaxing factor, ED: endothelial dysfunction, ROS: reactive oxygen species.

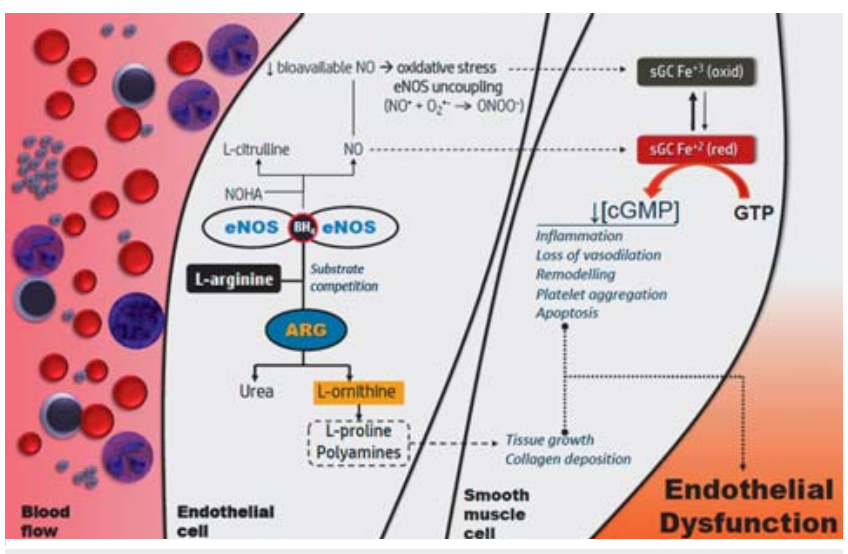

- Fig. 2 Mechanisms underlying ED, highlighting the substrate competition between nitric oxide synthase and arginase. ARG arginase, eNOS - endothelial nitric oxide synthase, $\mathrm{BH}_{4}$ - tetrahydrobiopterin, $\mathrm{NOHA}$ - N $\omega$-hydroxy-L-arginine, $\mathrm{NO}$ - nitric oxide, $\mathrm{O}_{2}{ }^{-}$- superoxide anion, $\mathrm{ONOO}^{-}$- peroxynitrite, $\mathrm{SGC} \mathrm{Fe}{ }^{+2}$ (red) reduced soluble guanylate cyclase, $\mathrm{sGC} \mathrm{Fe}{ }^{+3}$ (oxide) - oxidised soluble guanylate cyclase, GTP - guanosine triphosphate, cGMP cyclic guanosine monophosphate.

tion regarding the year of publication. The search terms that were used included "endothelial dysfunction" and "arginase" or "arginase inhibition", "nitric oxide" and "arginase" or "endothelial dysfunction", and "arginase inhibition" and "plant derived" or "natural compound" or "natural product" or "polyphenol".

The research publications that were included provided in vitro or in vivo results (human or rat/mouse) as well as revisions related to the proposed theme. The following were excluded: in vivo research with species of animals other than those mentioned above (it is important to note that studies using natural compounds such as inhibitors of Leishmania sp. ARG were not considered), unpublished studies, studies with incomplete information regarding references, and studies that were not in the format of a scientific article. The chemical names of the molecules presented in the course of this review are in agreement with those presented in the original references that were cited, and the scientific names of the plant species that are mentioned are in accordance with those mentioned in The Plant List (www.theplantlist.org).

For the in silico analysis, the oral bioavailability and distribution volume data were collected from ACD/I-Lab (https://ilab.acdlabs. com/iLab2/index.php). The ADME investigation, drug-likeness, and toxicity prediction were obtained through the PreADMET web programme (https://preadmet.bmdrc.kr/). The MDL molfiles of substances were loaded in these databases for calculations.

\section{Arginase: an overview}

ARG (L-arginine-urea hydrolase, or amidinohydrolase - EC 3.5.3.1) is a metalloenzyme that was first described in 1904 by Kossel and Dakin in mammalian liver samples [25]. Each active unit of the trimer is essentially two $\mathrm{Mn}^{+2}$ ions [6, 39]. The structure and stability of these ions are required for the full catalytic action of the enzyme [40].

During its catalytic cycle, the guanidine grouping of L-arginine undergoes a nucleophilic attack from a complex formed by $\mathrm{Mn}^{+2}$ and hydroxide ions from water molecules, forming a neutral, intermediate tetrahedral, and releasing L-ornithine and urea [6, 27, 40].

Since 1965, different ARG isoforms have been reported in human tissues [41-43]. In mammals, two of these isoforms are most prominent and, therefore, they are reported more frequently in the scientific literature, namely, ARG 1 and ARG 2 ( $\triangleright$ Table 1) $[11,41]$.

ARG isoforms are encoded by homologous genes that are mapped in distinct chromosomes (ARG 1 in chromosome 6q23 and ARG 2 in 14q24) [27,36,53-56]. A genetic sequencing study that was performed with human kidney tissue detected that the ARG 2 sequence was $58 \%$ homologous to that of ARG 1 [49], whereas human and mouse ARG 1 have $87 \%$ of the sequence in common [27]. This information is important because it points to- 
- Table 1 Some human characteristics of ARG 1 and 2.

\begin{tabular}{|c|c|c|}
\hline & ARG 1 & ARG 2 \\
\hline Amino acids & 322 & 354 \\
\hline Weight & 105 kDa & $129 \mathrm{kDa}$ \\
\hline$K_{m}$ & 0.08 at $\mathrm{pH} 8.5$ & 4.8 at $\mathrm{pH} 7.4$ \\
\hline Tissue distribution & $\begin{array}{l}\text { Endothelial cells, nephritic glomeruli, macrophages, liver, } \\
\text { erythrocyte, coronary arteries, corpora cavernosal, brain, } \\
\text { retinal glia, polymorphonuclear neutrophils, and saliva. }\end{array}$ & $\begin{array}{l}\text { Smooth muscle cells, endothelial cells, normal glomeruli, } \\
\text { macrophages, kidney, gastric cancer tissue, corpora caver- } \\
\text { nosal, brain, retina, and horizontal cells at heart, placenta, } \\
\text { lung, skeletal muscle, pancreas, and prostate. }\end{array}$ \\
\hline Inducers & $\begin{array}{l}\text { LPS, TNF } \alpha \text {, hyperglycaemia, nitric oxide, All, IL-1, and } \\
\text { glucocorticoids. }\end{array}$ & $\begin{array}{l}\text { IL-1, IL-4, IL-13, hypoxia, LPS, TNF } \alpha \text {, thrombin, oxLDL and } \\
\text { haemodynamic forces. }\end{array}$ \\
\hline Comments & $\begin{array}{l}\text { Is highly expressed in the cytosol of hepatocytes - } \\
\text { catabolic function to convert L-arginine in ureia } \\
\text { (ureia cycle). }\end{array}$ & $\begin{array}{l}\text { Is located within the mitochondrial matrix. Has widespread } \\
\text { tissue localisation and a relatively low specific activity } \\
\text { (in general, anabolic functions). }\end{array}$ \\
\hline References & {$[26,27,39,41,42,44-52]$} & \\
\hline
\end{tabular}

wards the identification of isoforms in human samples and makes it possible to investigate enzymatic induction under normal or pathological conditions.

In eukaryotic organisms, when they are active, both ARG isoforms take the homotrimeric form (105 kDa - ARG 1 and $129 \mathrm{kDa}-\mathrm{ARG} 2)[6,40,42]$. At this point, the maximum activity of ARG is about 1000 times greater than that of NOS, however, its affinity for L-arginine $\left(K_{m} 1-5 \mathrm{mM}\right)$ is lower when compared to the same enzyme $\left(K_{m} 2-20 \mu \mathrm{M}\right)[2,57]$.

ARG 1 is the largest fraction of the total ARG expressed in the organism [26]. It is present in the cytosol of liver cells, where it is an integrated part of the urea cycle (conversion of the L-arginine substrate to L-ornithine and urea) as well as other enzymes [Nacetylglutamate synthase (NAGS), carbamoylphosphate synthetase (CPS1), mitochondrial ornithine transporter (OTC), ornithine transcarbamylase (ASL) and argininosuccinatesynthetase-1 (ASS1)] $[2,47,53]$. ARG 2 is mitochondrial and can be found in several tissues, mainly in the kidney. This isoform has several roles that have not yet been fully defined, including participation in the synthesis of polyamines as well as the formation of proline, creatine, glutamate, agmatine, and $y$-amino-butyric acid (GABA) $[27,41,47,57]$.

Both ARG 1 and ARG 2 can be expressed in the vascular endothelium [31]. Despite some controversy about the expression of isoforms in the adjacent smooth muscle cell layer $[2,58]$, it has been shown that aortic smooth muscle tissues in rats express ARG 1 [59]. On the other hand, smooth muscle cells of human lung tissue express both isoforms [26, 55, 59]. In general, ARG expression can be modulated in different sites, depending on the stimulus that is applied $[7,41,55,60]$.

Furthermore, it has been demonstrated that iNOS-derived NO can nitrosate the sulphur of the cysteine residue 303 of ARG, activating the enzyme [61]. However, reduction in the levels of L-arginine caused by ARG activity may cause decreased iNOS activity [62]. These data suggest a bidirectional relationship between
ARG 1 and iNOS that could play an important role in vascular diseases [2].

In vitro and in vivo studies have demonstrated that LPSs increase the mRNA of ARG 1/ARG 2 and iNOS in different tissues, such as the lung, heart, liver, and endothelial cells of rats [41]. In parallel, other substances, such as THF- $\alpha$, high glucose concentrations, oxidised low-density lipoprotein, hydrogen peroxide or peroxynitrite, and thrombin may induce increased ARG expression (• Fig.3) [63]. Thus, inflammatory mediators modulate the expression of iNOS and ARG, depending on the cellular system that is involved $[41,64,65]$.

Interestingly, Nelin et al. [71] showed that an increase in ARG expression, whilst not affecting NOS levels, can result from the activation of the EGFR (expressed in endothelial cells). Likewise, it has been demonstrated that All led to an increase in ARG expression and activity in the mouse aorta [51]. Furthermore, the increased expression and stimulation of All receptors is associated with alterations in the activity of ARG [72].

Other conditions, such as hypertension, ischemia-reperfusion, intima layer hyperplasia, and aging, can elevate ARG levels, which is expressed in vivo in endothelial tissue [63]. Thus, in addition to its interaction with iNOS, ARG is also closely related to the maintenance of the functions of eNOS, which is an important enzyme isoform for the preservation of vascular homeostasis because the eNOS-derived NO acts to inhibit the vascular tonus, platelet aggregation, and inflammation [1,2]. Consequently, any alteration of the system orchestrated by NO may cause what is known as $E D$, and although the main effect of this disorder is damage to vasodilation mechanisms, it has also been reported that local inflammation, lipoperoxidation, SMC proliferation, deposition of extracellular matrix, and platelet and thrombotic activation can occur ( $\triangleright$ Fig. 2) [10].

Therefore, ARG is a regulator of the bioavailability of NO by competing with eNOS for the L-arginine substrate, and an increase in ARG activity and a consequent decrease in NO bioavailability are linked to the development of ED and its complications in 


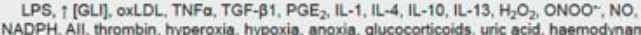
factors (hypertension, ischaemia-reperfusion or intimal hyperplasia), intracellular pathogens

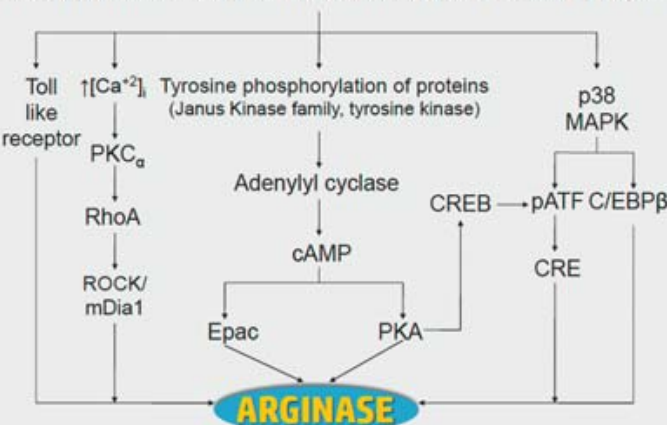

- Fig. 3 Pathways involved in arginase expression. Several humoral and haemodynamic factors, including intracellular pathogens and ROS, are part of the mechanism of ARG activation [26, 41, 46]. Intracellular pathogens (e.g., Mycobacterium tuberculosis) induced ARG expression through the toll-like receptor pathway [66]. The formation of pores in the endothelium and hyperpermeability in the lungs (as occurs in severe pneumonia) can increase intracellular calcium concentration, activating protein kinase C (PKC $\alpha$ ), which activates RhoA/ROCK to elevate ARG expression [67]. Similarly, the atherogenic stimulus oxLDL acts via the RhoA effectors ROCK and mDia1 to activate L-arginine catabolism by augmenting ARG levels [50]. Microgravity conditions activate the p38 MAPK (mitogenactivated protein kinase)-C/EBP $\beta$ pathway [68]. Furthermore, the induction of tyrosine phosphorylation of proteins, like the Janus kinase family (JAK1, JAK2) and tyrosine kinases (TyK-2), leads to adenylyl cyclase activity through a cAMP (cyclic adenosine monophosphate)/PKA or Epac pathway $[45,69]$. The ability of p38 MAPK to phosphorylate the activation transcription factor (pATF) suggests that p38 MAPK may modulate the expression of CAMP - responsiveelements (CRE). Furthermore, CRE-binding protein (CREB) can be activated by PKA and bind to PATF as a heterodimer to facilitate ARG transcription via CRE [70]. LPS - lipopolysaccharide, GLI - glucose, TNF $\alpha$ - tumor necrosis factor alpha, TGF- $\beta$ - transforming growth factor beta, $\mathrm{PGE}_{2}$ - prostaglandin $\mathrm{E}_{2}$, IL - interleukin, $\mathrm{H}_{2} \mathrm{O}_{2}$ hydrogen peroxide, ONOO ${ }^{*}$ - peroxynitrite, $\mathrm{NO}$ - nitric oxide, $\mathrm{NADPH}$ - dihydronicotinamide-adenine dinucleotide phosphate, All - angiotensin II.

the various diseases in which it is present. This emphasises why ARG has become the subject of studies regarding the development of inhibitors as new pharmaceutical tools [17, 18,61].

As previously mentioned, changes in NO bioavailability constitute the key event in the development of ED. Many mechanisms are involved in the decompensation of the NO supply, especially its inactivation due to oxidative stress (mitochondrial respiration, arachidonic acid cascade, cytochrome p450 complex, xanthine oxidase, NADH/NADPH oxidase, iNOS, peroxidases, and haemoproteins), which is associated with eNOS uncoupling and a decrease in the expression of this same enzyme, with or without a shortage of enzymatic or substrate cofactors (L-arginine) [13, 73].

Several studies have shown that blocking the advancement of $\mathrm{ED}$ is a powerful tool in reducing cardiovascular risks and, thus, many strategies have been investigated in order to prevent the development of ED or complications associated with it [16].
Compounds of natural origin, especially polyphenols with antioxidant activity, have been successfully tested in relation to ED [12,74-77]. Dal-Ros et al. [35] showed that the consumption of polyphenols in red wine protected against aging-related ED by normalising the oxidative stress that was induced in the animal model that was tested. Similarly, natural products have a recognised stabilising or stimulating effect on eNOS, which promotes an increase in NO levels, which are lower in $\operatorname{ED~}[12,30,65,78,79]$.

Another strategy that has been evaluated in studies regarding the treatment of diseases associated with ED is an attempt to provide physiological supplementation with L-arginine substrate, although this has produced controversial results that are related to limiting factors such as the consumption of this amino acid via alternative metabolic pathways, rapid metabolisation after oral administration, the need to screen patients who would clinically require $L$-arginine replacement, and the difficulties in determining individual levels of active ARG $[4,6,55]$. A controlled study of oral L-arginine supplementation conducted with patients with a history of myocardial infarction had to be discontinued because of the excessive mortality rate of the participants $[6,25]$. It has also been observed that the exposure of cell cultures to arginine may even precipitate endothelial senescence [15].

Furthermore, it should be taken into account that the intracellular level of arginine is higher (more than $800 \mu \mathrm{M}$ ) than the extracellular level $(50-200 \mu \mathrm{M})$. Given that the affinity of eNOS purified by this substrate is in the micromolar range of $\mathrm{K}_{m}=2.9 \mu \mathrm{M}$, it is suggested that eNOS operates below its saturation concentration, and therefore would not respond to changes in the concentration of circulating L-arginine, which would theoretically refute the alternative of supplementation with the semi-essential amino acid against ED $[6,12,80]$.

In fact, the chronic intake of L-arginine offers minimal therapeutic outcomes in vascular disease, showing that this substance is probably not a limiting factor regarding NO production. The exception may be when ARG is more active, reinforcing the competition with eNOS for the common substrate [15].

Thus, because a decrease in the bioavailability of NO has a central role in the mechanism of ED, and due to the fact that competition between eNOS and ARG for L-arginine can intensify this process, scientific efforts were concentrated in order to better investigate the role of ARG in this mechanism.

Scientific evidence began to emerge in the 2000s that ARG activity limited NO production by NOS, and that this was closely related to the depletion of endothelium-dependent vasodilation [81]. These results revealed the importance of ARG as a regulator of the process of the development of ED and transformed it into a new issue of interest for the scientific community regarding the search for new ways to block the degradation caused by ED in the various diseases in which it occurs ( $\triangleright$ Fig. 4) [82, 83].

In the period 1990-2011, more than 500 patents were registered in the field of new synthetic ARG inhibitors (425 were registered in the USA), most of which were boronic derivatives. Nevertheless, this constitutes a vast field of research, since many of the patented products still present problems related to pharmacodynamic and kinetic action (factors such as the lack of selectivity in relation to ARG 1 and ARG 2 isoforms, short half-life, loss of potency in physiological $\mathrm{pH}$, and intrinsic toxicity) $[6,25,27,63,84]$. 


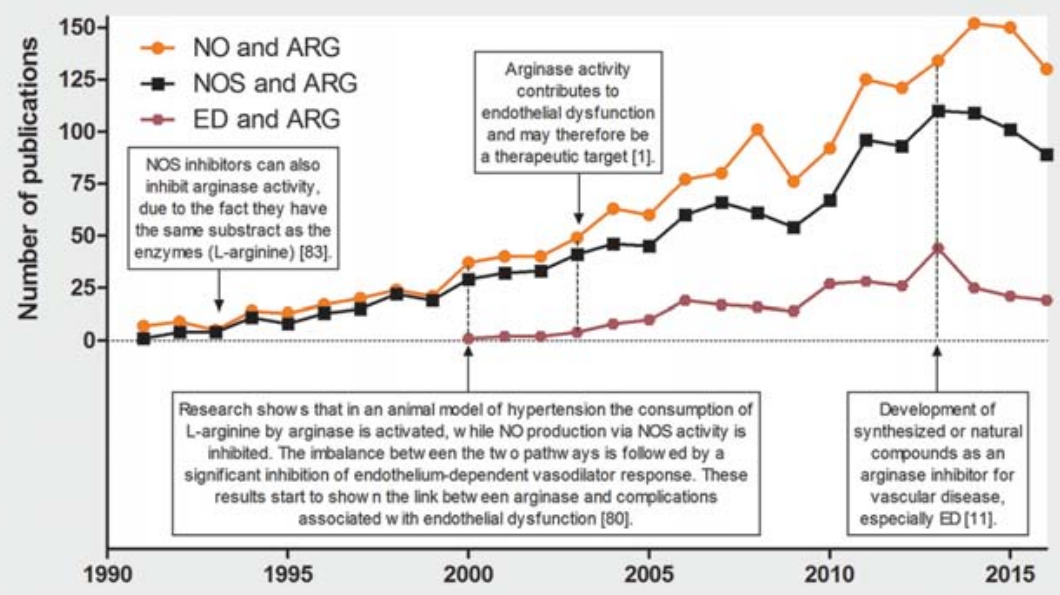

- Fig. 4 Development of research regarding the following: the involvement of arginase (ARG) in endothelial dysfunction (ED) (purple line), the perception of the existence of competition between nitric oxide synthase (NOS) and ARG (black line), and the consequent reduction of the bioavailability of NO (orange line). This resulted in increased interest in the research and development of ARG inhibitors with therapeutic appeal in relation to ED. The Pubmed database (December 2016) was used to obtain the data and "nitric oxide and arginase", "nitric oxide synthase and arginase", and "endothelial dysfunction and arginase" were applied as search terms.

In 2003, the U.S. Food and Drug Administration gave approval for a representative of boronic acid derivatives (bortezomib) to be used to treat multiple myeloma and mantle cell lymphoma [85, 86]. However, toxicological tests on rats and monkeys have indicated haematological, lymphoid, cardiac, renal, gastrointestinal, and neurological problems linked to its use, and data on its genotoxicity have not yet been published [6,25].

Thus, plants are a resource that is still little explored, but which have great potential. Research into new agents of natural origin has been gaining prominence as a source of interesting substances that can be used to develop new therapeutic options with low NO bioavailability $[5,11]$.

\section{Plants as a new source of arginase-inhibiting molecules: in vitro and in vivo evidence}

Different methods have been developed to study the inhibition of natural products in relation to ARG activity. In vitro techniques include a micro-immobilised enzyme reactor (IMER), which uses ARG that is covalently bound to an ethylenediamine monolithic convective interaction media disk submitted to an HPLC system. Using this procedure, a procyanidin-enriched extract of the stem bark from Ficus glomerata Roxob was assessed by simultaneous injection with an enzyme substrate (nitro guanidine benzene). As a result, the enzyme $K_{m}$ values did not change, but the $V_{\max }$ decreased due to a high quantity of polymers that affected the enzyme proximity and orientation. This demonstrated, for the first time, the direct action of plant-derived compounds on ARG activity and the modifications induced on it [58].

Interestingly, the hypothesis of a molecular interaction effect between isolated substances, or plant-derived extracts and ARG, has been little explored in the literature. From this point of view, polyphenolics have an important role to play due to their ability to alter the active conformation of enzymes by destabilising the bonds between hydrogen bonds and water molecules [27].

Akanni et al. [87] tested the effects of the methanolic extracts of the African species Artocarpus altilis (Parkinson ex F.A.Zorn) Fosberg (stem bark), Ficus exasperata Vahl (leaves), Kigelia africana (Lam.) Benth. (fruits), and catechin in relation to samples of cardiac ARG. The in vitro results indicated that $F$. exasperata and $K$. africana were not effective, whereas $A$. altilis and catechin (both tested at 500 and $700 \mu \mathrm{g} / \mathrm{mL}$ ) inhibited enzymatic activity in 63, 67,42 , and $52 \%$ of cases, respectively, when compared to the control.

The rhizomes of ginger [Zingiber officinale Roscoe (Zingiberaceae)] and saffron, which is better known as red ginger [Curcuma longa L. (Zingiberaceae)] (2 and 4\%) were included in a diet that was rich in cholesterol (2\%) that was given to rats for 14 days. At the end of the trial period, it was shown that there was a significant reduction in the ARG activity measured in the plasma and liver of the treated animals when compared to the control. In addition, the presence of gallic acid, catechin, caffeic acid, epicatechin, rutin, quercetin, quercetrin, campherol, luteolin, and curcumin in samples of the rhizomes was noted, and the results that were obtained were attributed to these substances because an inverse correlation was observed between the consumption of phenolics (flavonoids) and the total concentration of plasma cholesterol $[17,88]$.

These results have contributed to the study of the application of new ARG inhibitors in cardiovascular alterations, since the ED involved in these situations would be impeded by the inhibition of the enzyme, resulting in a greater blood supply (NO-mediated vasodilatation) to the tissues. Spontaneously hypertensive rats showed low pressure rates and improved endothelial function when submitted to ARG inhibition [58]. 
Other studies have also tested dietary supplementation with plant extracts to inhibit in vivo ARG activity. Wistar rats (male, adults) were sprayed with $400 \mu \mathrm{L}(200 \mathrm{mg} / \mathrm{Kg})$ of the aqueous extract of Yucca schidigera Roezl ex Ortgies (Asparagaceae) (Mohave yucca) and the fractions were obtained by the partition of the extract with $n$-butanol. At the end of the 76 days of the experiment, a significant decrease in hepatic ARG activity was observed in the animals treated with the total aqueous extract of $Y$. schidigera and with its $n$-butanolic fraction $(p=0.03)$ [89].

Similarly, Schnorr et al. [29] performed a study regarding the action of a cocoa drink that was either poor $(<90 \mathrm{mg})$ or rich $(985 \mathrm{mg})$ in flavanols. This mixture provided (-)-epicatechin $(0.1 \mu \mathrm{M})$ and catechin $(0.4 \mu \mathrm{M})$ as well as the metabolites epicatechin-7- $\beta$-glucuronide $(0.25 \mu \mathrm{M}), \quad 4$ '-O-methyl-epicatechin $(0.2 \mu \mathrm{M})$, and $44^{\prime}$-O-methyl-epicatechin-7- $\beta$-glucuronide $(1.7 \mu \mathrm{M})$ (values of plasma concentration measured after $2 \mathrm{~h}$ of consumption of $200 \mathrm{~mL}$ of cocoa beverage that provided $2.6 \mu \mathrm{M}$ of flavonoids) in healthy humans ( 2 days). A protein diet containing 0 or $4 \%$ cocoa powder was provided to male rats ( 28 days). As a result, in the samples of erythrocytes taken $24 \mathrm{~h}$ after the end of the experiment, those that belonged to the flavonoid-rich cocoa beverage group showed a decrease in the active ARG portion. A reduction in the enzymatic activity of the renal ARG in the rats was also observed.

Corroborating this, in vitro testing of ARG inhibition in HUVEC cells shows that both (-)-epicatechin and its mixture of flavanol metabolites exhibited effects, suggesting that after metabolisation, polyphenols can retain anti-ARG activity (at least under controlled conditions) [29].

Taken together, these results show that the in vivo inhibition of both isoforms of the enzyme is possible, which is represented by the previously cited results regarding ARG 1 and ARG 2 obtained in different tissues, where each of them are mostly expressed and active. Furthermore, this demonstrates that at this level it is important to understand the biological effects of low levels of enzymatic activity and its correlation with the responses that are obtained. On the other hand, research regarding ARG activity using in vitro techniques is still valuable because it makes it possible to predict behaviours and mechanisms for the models on which therapeutic applications are based.

The ethyl acetate extract of the lignum of Caesalpinia sappan L. (Leguminosae), which is used in Asian culture to promote improved circulation and also to prevent blood stasis, was evaluated in relation to ARG 2 of the kidney lysate of C57BL/6 mice as well as in HUVEC cells. As a result, residual activity in ARG 2 was observed $(31 \%)$ at the highest concentration of the extract used $(50 \mu \mathrm{g} /$ $\mathrm{mL}$ ), and the calculated $\mathrm{IC}_{50}$ was $36.82 \mu \mathrm{g} / \mathrm{mL}$. In the other experiment that was conducted, after $18 \mathrm{~h}$ of incubation with $20 \mu \mathrm{g} / \mathrm{mL}$ of the extract, a significant decrease in enzymatic activity was observed when compared to the untreated control [90].

The aforementioned study also demonstrated that with the inhibition of the ARG in the HUVEC cells there was a dose-dependent increase in NO production, with a maximum level of $130 \%$ at $50 \mu \mathrm{g} / \mathrm{mL}$. This data highlights the relationship between decreased levels of active ARG and increases in NO, which serves as a basis for ethnopharmacological applications of $C$. sappan, given the antithrombotic and provascular properties of NO [90].
A further two published studies that evaluated the use of the aqueous extract of Korean red ginseng [Panax ginseng C. A.Mey (Araliaceae)] to improve endothelial function impairment associated with age (in atherosclerosis models) reached similar conclusions; the extract (10-20 mg/mouse/day during 4-6 weeks) inhibited ARG activity in a nonselective manner, causing an increase in eNOS dimerisation and a consequent increase in NO levels, which strengthened the vasodilatation dependent on this mediator. Moreover, active components of Korean red ginseng (ginsenoside Rb1 and Rg3) have been linked to increased NO production in endothelial cells by the activation of the phosphoinositide 3-kinase (PI3K)/PKB intracellular pathway (also known as Akt, which is a serine/threonine-specific protein kinase) [91, 92].

Concrete evidence supports the involvement of ARG 1 and ARG 2 in the pathophysiology of erectile dysfunction. Because NO serves to relax the smooth muscles of the corpus cavernosum, inhibition of ARG, at this time, is useful for increasing the supply of the substrate to the action of eNOS [93].

Oboh et al. [38] found that extracts of the leaves of Moringa oleifera Lam. inhibited ARG from rat penis homogenates in a dose-dependent manner ( $\left(\mathrm{C}_{50}\right.$ of $159.59 \mu \mathrm{g} / \mathrm{mL}$ ). In the aforementioned study, the authors identified the polyphenol composition of the extract (gallic acid, catechin, chlorogenic acid, ellagic acid, epicatechin, rutin, quercitrin, isoquercitrin, quercetin, kaempferol), which, in their opinion, contributed greatly to the mechanism of action against erectile dysfunction.

Of the secondary metabolites that have been isolated from plants, polyphenols have been extensively tested against ARG as a tool to control diseases attributed with the advancement of ED $[11,25,27,29,36,38]$.

Using an indirect technique (the quantification of urea produced), Reis et al. [94] found that at a concentration of $1 \mathrm{mM}$, the polyphenols (-)-epigallocatechin-3-gallate, (+)-catechin, $(-)$-epicatechin, and gallic acid were able to inhibit the activity of ARG isolated from rat liver by $29,26,22$, and $20 \%$, in that order.

Nelin et al. [71] used immunoblotting and Real-Time PCR methods in relation to ARG 1 (bovine pulmonary arterial endothelial cells) and ARG 2 respectively, to demonstrate that the induction of the expression of these enzymes by a mixture of LPS/TNF$\alpha$ partially depended on the activity of the EGFR, and that the flavonoid genistein acted indirectly on the expression of ARG as an EGFR inhibitor.

Using a low-cost in vitro colorimetric technique with commercially available b-ARG 1, Bordage et al. [34] determined the ARG inhibitory potential of a range of polyphenols. Other studies, which used some changes in this technique, also evaluated the anti-ARG action of several phenolics in vitro ( $\bullet$ Table 2 ).

As can be seen in $\mathbf{r}$ Table $\mathbf{2}$, the most active phenolics were chlorogenic acid and piceatannol, and the efficacy was similar to the positive control that was used, with $\mathrm{E}_{\max }$ values of 81 and $98 \%$ for the phenolics respectively, and an $E_{\max }$ of $97 \%$ for the BEC. It was also observed that there was competitive inhibition behaviour between these phenolics and b-ARG 1 .

In relation to the study of the activity structure relationship, according to the $\mathrm{IC}_{50}$ data obtained in two recent studies, the caffeoyl (3,4-dihydroxycinnamoyl) group appears to be essential, since both chlorogenic acid and piceatannol have this substituent 
- Table 2 ARG inhibition of important polyphenols from a medicinal chemistry point of view.

\begin{tabular}{l|l|l|l|l} 
Substance & Structure \\
\hline Chlorogenic acid & \\
\hline &
\end{tabular}

Piceatannol $^{a}$

Resveratrol $^{a}$

(-)-Epicatechin $a$

19.9

Taxifolin $^{a}$

OH

23.2

Quercetin $^{a}$

(1)

18.2

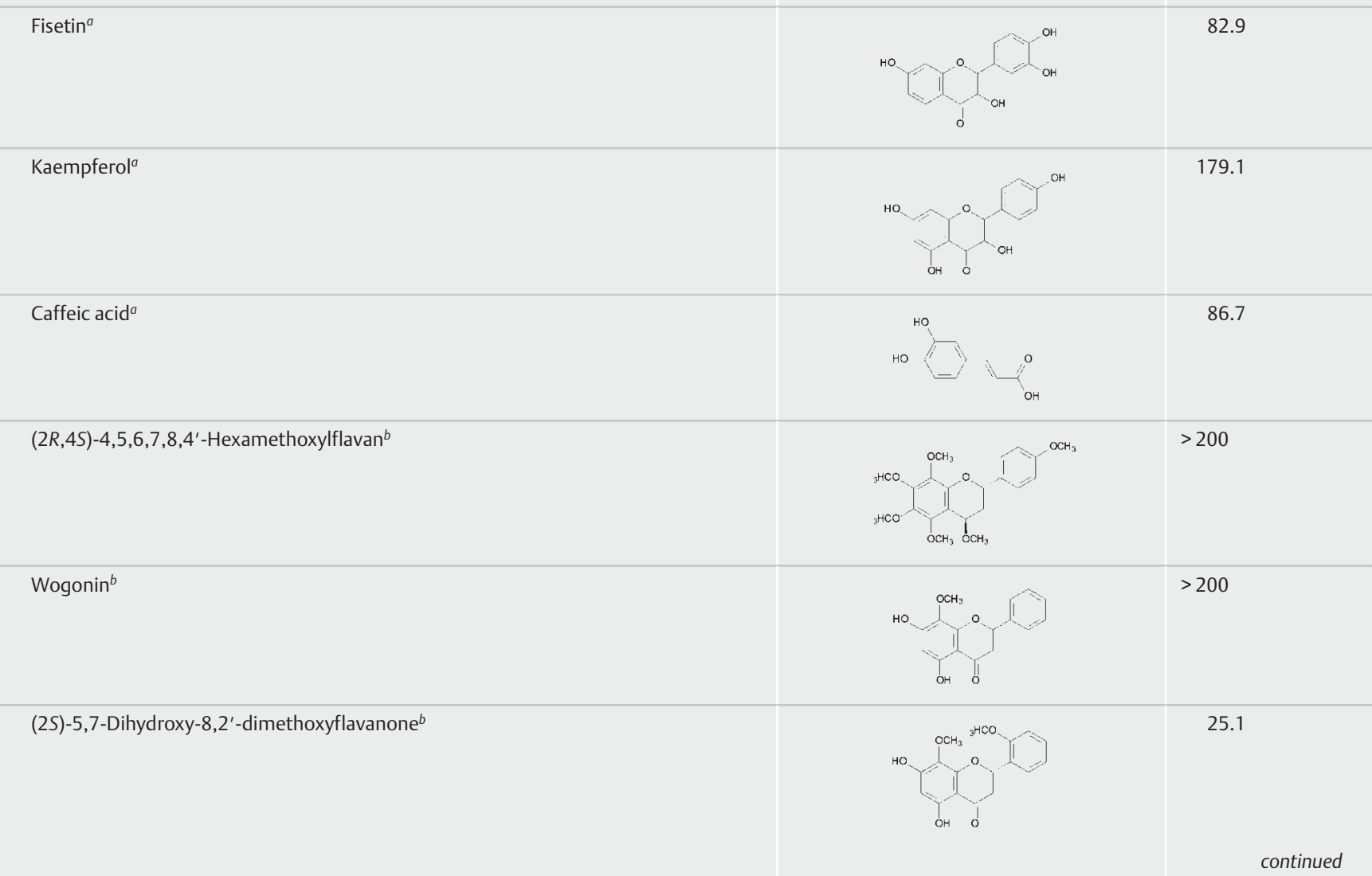

Wogonin $^{b}$

${ }_{\mathrm{O}}^{\mathrm{OH}}$

82.9

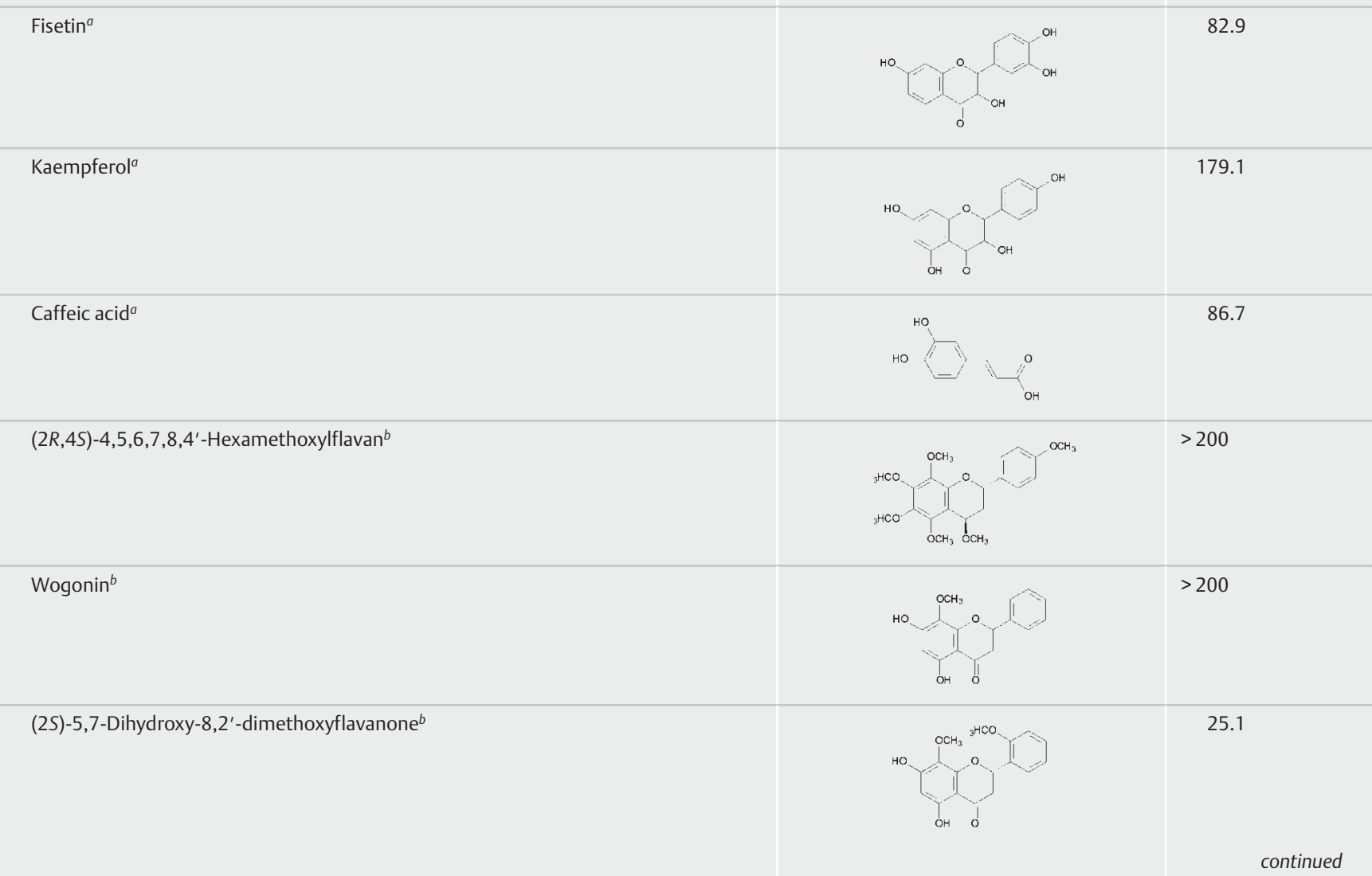

Caffeic acid ${ }^{a}$

HO

86.7

но

31.2 
- Table 2 Continued

\begin{tabular}{|c|c|c|}
\hline Substance & Structure & $\mathrm{IC}_{50}(\mu \mathrm{M})$ \\
\hline Apigenin ${ }^{b}$ & & $>200$ \\
\hline (2S)-5,2', 5'-Trihydroxy-7,8-dimethoxyflavanone ${ }^{b}$ & & 11.6 \\
\hline Naringenin ${ }^{b}$ & & $>200$ \\
\hline Naringenin-5-O- $\beta$-D-glucopyranoside ${ }^{b}$ & & $>200$ \\
\hline (2S)-5,5'-Dihydroxy-7,8-dimethoxyflavanone-2'-O- $\beta$-D-glucopyranoside ${ }^{b}$ & & $>200$ \\
\hline 7-Hydroxysauchinone ${ }^{c}$ & & 89.6 \\
\hline Sauchinone $^{c}$ & & 61.4 \\
\hline meso-Dihydroguaiaretic acidc & & $>200$ \\
\hline Guaiacinc & & $>200$ \\
\hline
\end{tabular}


- Table 2 Continued

\begin{tabular}{l} 
Substance \\
$(7 \mathrm{~S}, 8 R)$-4-Hydroxy-3,7-dimethoxy-1 ${ }^{\prime}, 2^{\prime}, 3^{\prime}, 4^{\prime}, 5^{\prime}, 6^{\prime}, 7^{\prime}$-heptanorlign-8'-onec \\
\hline (E)-7-(4-Hydroxy-3-methoxyphenyl)-7-methylbut-8-en-9-one \\
Licarin Ac
\end{tabular}

in their structure. This is reinforced by the fact that in isolation, caffeic and quinic acids did not present satisfactory enzymatic inhibition when compared to the whole molecule. In relation to the derivatives of the flavonoid class, whose prototype is quercetin, pertinent observations include the importance of hydroxyl in C5 for the maintenance of activity, while the presence of the carbonyl group in C4 and the unsaturation at the C2-C3 bond exerted less significant influence, as well as the fact that the substitutions of hydroxyl, glucose, or acetate at the $\mathrm{C} 3, \mathrm{C} 7, \mathrm{C} 8$, and $\mathrm{C2}{ }^{\prime}$ positions appear to have had no positive influence on the inhibition of arginase. Furthermore, the hydroxyl in C5' (catechol group) is essential to the inhibitory activity as well as the $\alpha$ bond between C2-C1', which increases the activity ( $\bullet$ Fig. 5) $[34,36]$.

Based on the in vitro results obtained by Kim et al. [36], who tested eight flavonoid-type substances isolated from a methanolic extract of Scutellavia indica L. in relation to ARG 2 from mouse kidney homogenate, another group of researchers sought to perform more in-depth in vivo research regarding the anti-ARG properties of the substance TDF, which had been previously isolated. In that study, the authors used a hyperlipidemia model to demonstrate that TDF inhibited both ARG 1 (IC 50 of $12.18 \mu \mathrm{M})$ and ARG 2 (IC 50 of $11.86 \mu \mathrm{M})$ in a noncompetitive manner, simultaneously increasing NO levels by the phosphorylation and dimerisation of eNOS, as well as indicating an improvement in vascular function in normal mice that received a standard diet, and also $\mathrm{ApoE}^{-1-}$ mice fed on a high cholesterol diet [96].

In the study by Kim et al. [36], referred to above, PG was used as a positive control ( $\mathrm{IC}_{50}$ of $\left.1.0 \mu \mathrm{M}\right)$.

Piceatannol $\left(3,3^{\prime}, 4^{\prime}, 5\right.$-transtetrahydroxystilbene) is naturally found in rhubarb rhizomes [Rheum undulatum L. (Polygonaceae)] and can be metabolised from resveratrol through hydroxylation by the action of cytochrome P4501B1 [97]. The stilbene derivative PG was first evaluated by Woo et al. [65] and it showed antioxidant capacity and important inhibitory in vitro action in relation to ARG 1 and ARG 2, which was associated with the dose-dependent increase in NO levels. In the experiments, PG behaved as a nonselective ARG inhibitor in C57BL/6 mice (IC 50 of $11.22 \mu \mathrm{M}$ for liver lysate and $\mathrm{IC}_{50}$ of $11.06 \mu \mathrm{M}$ for kidney lysate) and was able to

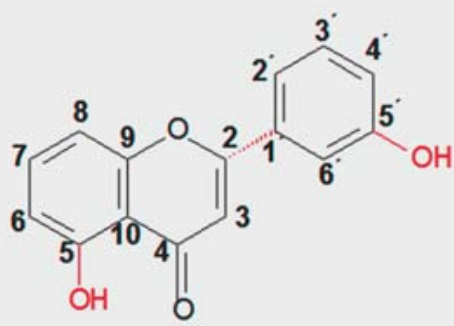

- Fig. 5 Structure-activity relationships of flavonoid-type polyphenols as arginase inhibitors. Highlights in red lines indicate important parts of the molecule in relation to anti-arginase action; the hydroxyl group $(-\mathrm{OH})$ at $\mathrm{C}^{\prime}$ and $\mathrm{C} 5$ and the $\alpha$ bond between $\mathrm{C2}-\mathrm{C1}^{\prime}$ are essential for the activity.

increase NO production and decrease ROS in isolated aortic fragments.

Inspired by these results regarding the potential of PG, Frombaum et al. [98] compared the behaviour of resveratrol and piceatannol in relation to BAEC. The effects were measured in BAEC that was stimulated by high concentrations of glucose $(25 \mathrm{mM})$ for $24 \mathrm{~h}$ in order to mimic the hyperglycaemic conditions observed in the diabetes state. As a result, both resveratrol $(10 \mu \mathrm{M})$ and $\mathrm{PG}$ aglycone $(1 \mu \mathrm{M})$ were shown to produce enzymatic inhibition in the experiments; the efficacy of the latter was considered to be greater, sustaining its therapeutic potential for application in relation to $\mathrm{ED}$.

The research group led by Woo et al. [99] subsequently proved that the administration of PG $(\sim 500 \mu \mathrm{g} /$ mouse/day for 6 weeks) was able to improve ED in an animal model of hyperlipidaemia via ARG inhibition and, reciprocally, eNOS activation through enhanced stability of the eNOS dimer.

Based on these results, a review was published regarding the effects of piceatannol on the diversity of cardiovascular impairment, including the prevention of hypercholesterolaemia, cardiac arrhythmia, monocyte adhesion to the endothelium, proliferation 
and migration of SMCs, ED, and angiogenesis, as well as its antiinflammatory, vasorelaxant, and antioxidant effects [97].

However, the application of piceatannol, or its derivative glucopyranoside, as a pharmaceutical product to reduce cardiovascular risks is limited due to its low oral bioavailability and a lack of studies regarding its pharmacokinetic profile [84, 97].

In an attempt to contribute to resolving these problems, Nguyen and Ryoo [100] proposed a study regarding the intravenous administration of piceatannol in mice with endothelial function compromised by old age. The animals (C57BL/6, male, 65 weeks) received injections of piceatannol $(30 \mathrm{mg} / \mathrm{Kg}$ body weight/day) over 4 consecutive days, after which time the tissues of interest were properly treated for subsequent analysis. In conclusion, the in vivo potential for ARG inhibition of piceatannol as well as its ability to improve the vascular function of senescent mice was reinforced by the increase in NO production by the phosphorylation of eNOS Ser1177 and the stabilisation of its dimer, strengthening the results obtained by Woo et al. [99] with the glucuronidated form of the stilbene derivative.

Thus, according to the promising results that have been obtained with piceatannol and PG, and in view of its structural similarity to resveratrol, $\mathrm{Yi}$ et al. [30] identified a new substance, THSG, ( $\triangleright$ Fig.6) from the Polygonum multiflorum Thunb (Polygonaceae) rhizome and tested it as an ARG inhibitor and eNOS activator. According to the authors, the mechanisms by which THSG acts are similar to those found for TDF, i.e., the restoration of vasculature function by the inhibition of ARG 1 and ARG 2 (25 and $38 \%$, respectively, at $50 \mu \mathrm{M}$ ), the increase of NO, and the decrease in ROS formation by the phenomenon of uncoupled eNOS. In addition, it was identified that THSG presented noncompetitive inhibition in relation to ARG 2 [96].

According to a survey, in vitro and in vivo research carried out in recent years supports the fact that numerous polyphenols that are derived from the most diverse plants are active in improving endothelial function by increasing NO bioavailability. In accordance with epidemiological investigations, basic and clinical research studies suggest that polyphenols demonstrate beneficial effects for the maintenance of vascular homeostasis in animal models as well as in humans [24].

Other phenolic substances have also been tested as inhibitors of ARG activity or expression with a view of developing new pharmaceutical products to be used regarding ED-related problems.

Quercetin is widely known for its multifaceted biological action and has shown promising anti-ARG results, although only in a limited fashion thus far (only one scientific publication was located). Nikolić et al. [88] induced a model of acute renal failure in adult male rats by the intramuscular injection of $50 \%$ glycerol $(8 \mathrm{~mL}$ ) $\mathrm{Kg}$ ) with pretreatment $(2 \mathrm{~h})$ of subcutaneous quercetin $(20 \mathrm{mg} /$ $\mathrm{Kg}$ ). As a result, the flavonoid was able to decrease levels of plasma urea and creatinine, as well as decreasing hepatic ARG activity when compared to the control group (glycerol only). According to the researchers, the established antioxidant action of quercetin, combined with the inhibition of L-arginine consumption (antiARG effect), may have contributed to the provision of a substrate for the synthesis of NO, whose vasorelaxant power contributed to decreasing vascular resistance and restoring renal function.

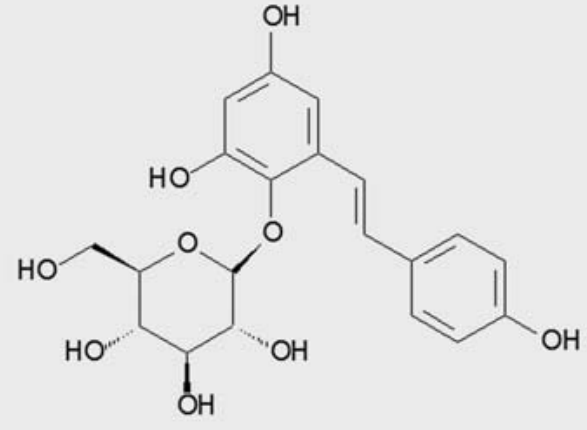

- Fig. 6 Molecular structure of 2,3,5,4'-tetrahydroxystilbene-2-O$\beta$-D-glucoside isolated from the rhizome of $P$. multiflorum Thunb. (Polygonaceae).

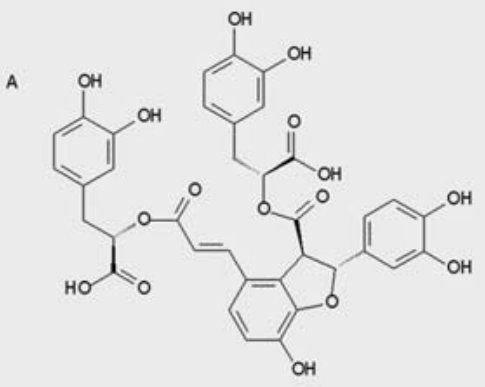

B

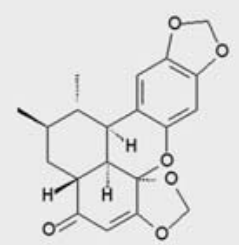

- Fig. 7 Molecules of salvianolic acid B (A), and sauchinone (B).

Other substances with important action against ARG include the polyphenolics salvianolic acid B [isolated from Salvia miltiorrhiza Bunge (Lamiaceae)] [101] and sauchinone [isolated lignan from Saururus chinensis (Lour.) Baill. (Saururaceae)] [95] (• Fig. 7).

Both of these substances are active in inhibiting ARG, particularly salvianolic acid B, which also decreased the expression of iNOS in RAW 264.7 macrophages that were induced by LPS [84, 101].

Such decreased levels of iNOS provide protection from the toxic effects of high NO concentrations derived from this high throughput isoform and, together with reduced ARG activity, this enhances the potential of salvianolic acid B against cardiovascular diseases associated with ED.

It is also worth mentioning that ellagic acid has received special attention from researchers because of its pluripotent biological activity and the multiple molecular targets that it acts upon [102]. Based on this, an animal model of hepatocellular carcinoma 
demonstrated that the oral administration of ellagic acid $(50 \mathrm{mg} /$ $\mathrm{Kg} /$ day), 7 days before and 14 days after tumour induction ( $\mathrm{N}-\mathrm{ni}$ trosodiethylamine and $\mathrm{CCl}_{4}$ ), provided $23.6 \%$ of inhibition of ARG activity when compared to the negative control group (healthy rats). In that particular study, the elevation of ARG levels after the injection of the tumour agent was considered a marker of disease progression, and other studies have also attributed a biomonitoring function to this enzyme in the most varied clinical conditions, such as the oxidative stress observed in pregnant, overweight women and their neonates [103, 104].

It is interesting to note that ARG activity is related to tumour progression, since the formation of polyamines and proline that are the result of enzyme action can contribute to cell proliferation and tumour growth, as shown by studies that have found a relationship of risk between the increased expression of ARG 2 and the appearance of disease $[93,105]$. Thus, ARG inhibition has the potential to curb this process, which might work in favour of the action of other anticancer substances.

Stolarczyk et al. [105] studied the aqueous and ethyl acetate extracts (aerial parts) of three species of Epilobium sp. [Epilobium angustifolium L., Epilobium parviflorum Schreb, and Epilobium hirsutum L. (Onagraceae)], as well as polyphenols isolated from these species, in relation to the ARG of prostate cancer (LNcaP) cells and demonstrated that almost all the extracts $(50$ and $70 \mu \mathrm{g} / \mathrm{mL}$ ) and phenolics that were tested, which included quercetin-3-Oglucuronide and oenothein B (20 and $40 \mu \mathrm{M})$, were able to significantly inhibit enzymatic action.

Furthermore, the same authors provided valuable data regarding anti-ARG research. They made an incubation of $E$. hirsutum herb extract, which contains high concentrations of oenothein $B$ (dimeric macrocyclic ellagitannin), with human gut flora (final concentration $1.6 \mathrm{mg} / \mathrm{mL}$ ) for $48 \mathrm{~h}$. After this time, the metabolites urolithins $A, B$, and $C$, which can be detected in plasma (0.5$18.6 \mu \mathrm{M})$, were produced and then tested for anti-ARG potential in LNcaP cells. The results showed that both urolithin A (ARG activity of $39.8 \pm 2.5$ mUnits of urea/mg protein) and C (ARG activity of $27.9 \pm 3.3 \mathrm{mUnits}$ of urea/mg protein) were active as enzyme inhibitors compared with the control cells $(65.2 \pm 1.1 \mathrm{mUnits}$ of urea/mg protein), whereas urolithin B was inactive. Thus, these data suggest that anti-ARG activity remains in metabolites as well as in its precursor compound, at least under in vitro conditions.

Indeed, the amount of ellagitannins in systemic circulation and tissues is virtually undetectable, whereas urolithins and their conjugates can be found in higher levels $(\mu \mathrm{M})$. It has been reported that ellagitannin metabolites can be detected in the liver and kidneys [106], urolithins are enhanced in the prostate, intestinal tissue, and colon in mice, and urolithin A-glucuronide is the main metabolite found in the human prostate ( $>2 \mathrm{ng} / \mathrm{g}$ tissue) as well as traces of urolithin B-glucuronide and ellagic acid-dimethyl ether $[102,107]$.

Regarding the plasma concentration, the level of polyphenols and their metabolites found in vivo needs to be biologically applicable and should also be taken into account. Engler et al. [108] found that the consumption of chocolate containing high levels of flavonoids improved endothelial function and increased the plasma concentrations of epicathecin (already reported as an
ARG inhibitor) in healthy adults, with a marked increase after 2 weeks (204.4 $\pm 18.5 \mathrm{nmol} / \mathrm{L})$.

Other studies have been performed to better characterise the absorption and metabolism of polyphenols, which would help to shed light on the pivotal relationship between the bioavailable amount and the biological effect. In an ex vivo experiment to measure NO-dependent vasodilation, Schroeter et al. [109] performed an incubation of preconstricted rabbit aortic rings with a mixture of flavanols and their metabolites (catechin, epicatechin, 4 '-methyl-epicatechin, epicatechin- $O-\beta$-D-glucuronide, and 4' $-O$ methyl-epicatechin-O- $\beta$-D-glucuronide) in the same higher plasma concentration achieved after 2 hours of administration, resulting in relaxation $(74.2 \pm 14.5 \%)$.

However, there is still a lack of data about the pharmacokinetics of plant-derived compounds. Characterisation of factors such as absorption, distribution, metabolism, excretion (ADME), and toxicological parameters may help to improve the evaluation of the drug-likeness features of plant-derived substances. For this purpose, methods of drug-likeness prediction have been developed (drug database screens, knowledge-based methods, and functional group filters) and they serve as valuable tools, especially in the pharmaceutical field [110] ( $\bullet$ Tables 3 and 4 ).

The potential therapeutic properties of bioactive substances depend on their bioavailability after oral administration. Therefore, matrix effects (for example, the vehicle for solubilisation or composition of the diet), the physical and chemical properties of the substance (degree of glycosylation/acylation, basic structure [benzene or flavones], conjugation with other phenolics, molecular size, degree of polymerisation, solubility/partition coefficient), interindividual variations (gastrointestinal secretions, motility, blood/lymph flow, etc.), and other interactions (alcohol or the presence of macronutrients like fat, protein, and carbohydrates) can be important factors to be considered in relation to the bioavailability of natural substances as well as the dosage used. Furthermore, gastric $\mathrm{pH}$, enterocyte metabolism, digestive enzyme activity, first pass metabolism, and mechanisms of resistance (expression of apical multidrug resistance-associated proteins such as P-glycoprotein 1) should all be considered [111-114].

Aglycones, simple phenolic acids, and flavonoids can be absorbed in the stomach or small bowel mucosa. If this does not occur, the phenolic substance will be carried to the colon, which contains catalytic and hydrolytic potential that is powered by microorganisms. This colonic microflora transforms polyphenols (glycoside derivates with a hydrophilic nature and relatively high molecular weight) into more simple substances, such as phenolic acids (aglycone) [115]. In addition, bile plays a pivotal role in the adsorption of plant-derived polyphenols from the gastrointestinal tract (enterohepatic cycle) [116].

As shown in > Table 3, all the reviewed polyphenols with antiARG potential are moderately or well absorbed (human intestinal absorbed and $\mathrm{Caco} 2$ permeability), but this inversely correlates with oral bioavailability (a minority have good parameters). It is suggested that this is due to first-pass metabolism, which extensively alters the quantities of substances in plasma.

Manach et al. [117] evaluated data from 97 studies about kinetics and the absorption of polyphenols among adults (the ingestion of a single dose of the substance). They found that gallic 


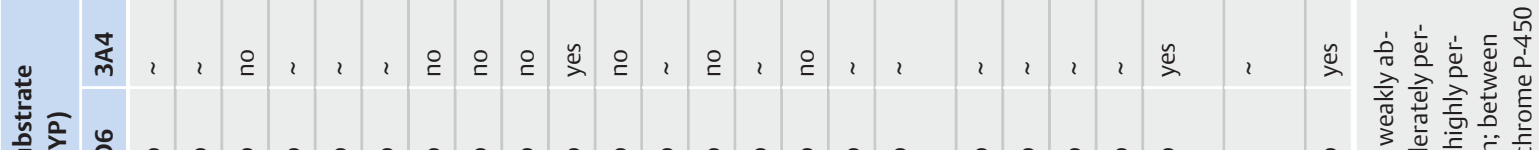

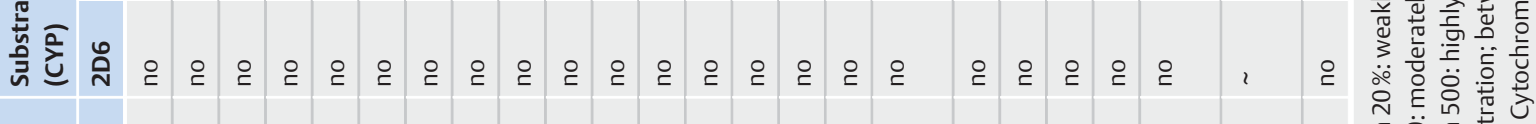

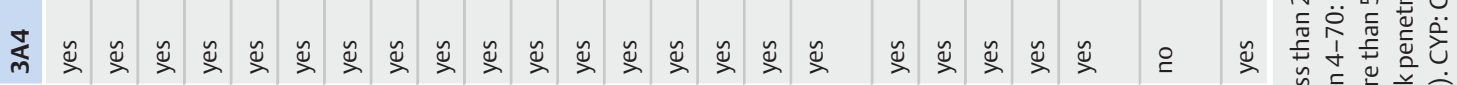

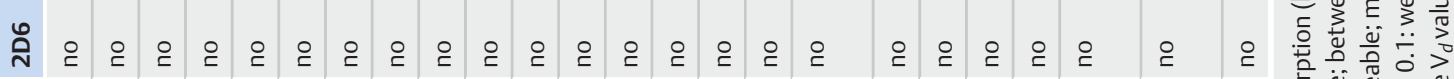
ह

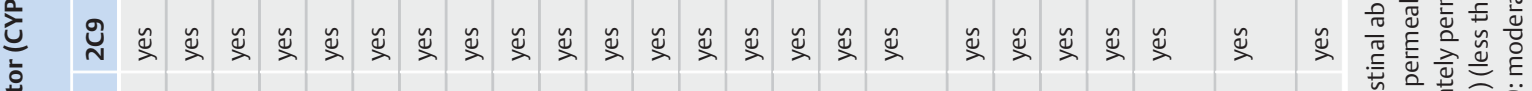

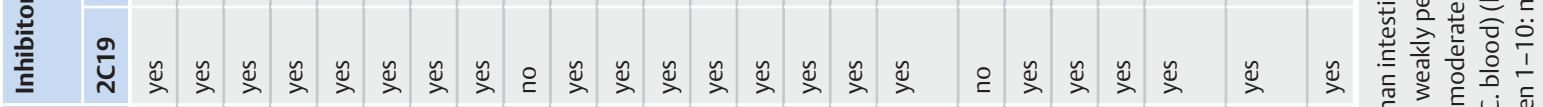

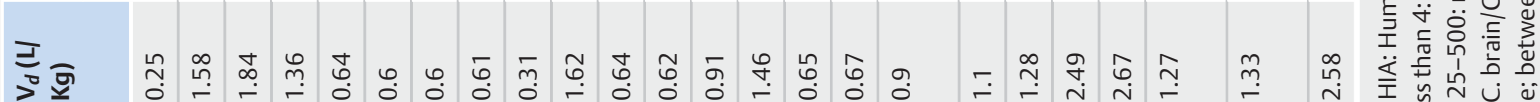
立 帛

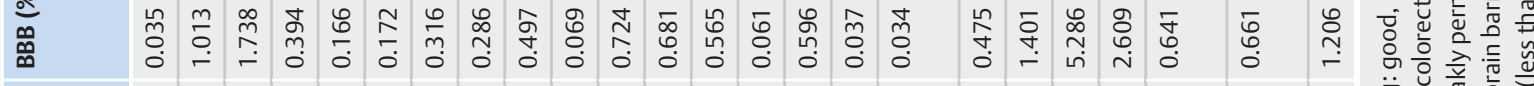
ฮ

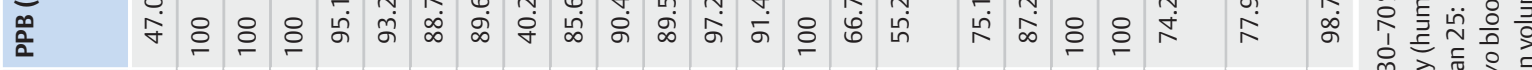

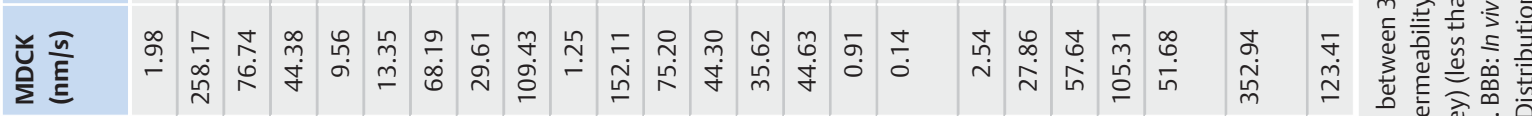

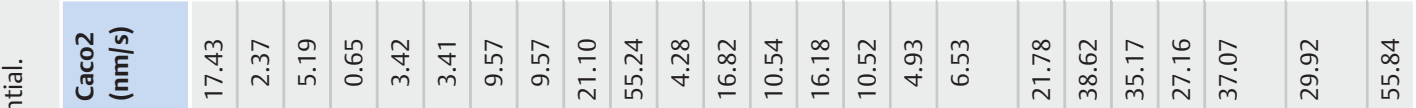
i 을

\begin{tabular}{|c|c|c|c|c|c|c|c|c|c|c|c|c|c|c|c|c|c|c|c|c|c|c|}
\hline 㞼 $\overline{\underline{\varepsilon}}$ & $=$ & 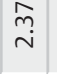 & เ & 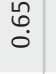 & & $\stackrel{\nabla}{m}$ & & & นึ้ & & 㒸 & & $\stackrel{\circ}{\circ}$ & $\stackrel{2}{+}$ & นึ่ & $\stackrel{\bar{\sim}}{\bar{N}}$ & & $\sqrt{7}$ & 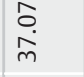 & & & .อ \\
\hline 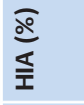 & $\begin{array}{l}\text { Na } \\
\text { ì }\end{array}$ & 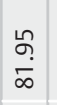 & $\begin{array}{c}\underset{f}{f} \\
\infty \\
\infty\end{array}$ & $\begin{array}{l}? \\
\dot{0} \\
0\end{array}$ & $\begin{array}{l}0 \\
\dot{8}\end{array}$ & 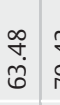 & fo & 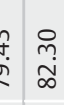 & $\begin{array}{l}\infty \\
\infty \\
\infty \\
\infty\end{array}$ & $\begin{array}{l}\tilde{n} \\
\tilde{m}\end{array}$ & $\begin{array}{l}\hat{\sigma} \\
\text { ু̀ }\end{array}$ & $\begin{array}{cl}c & \infty \\
\infty & d \\
\infty & b \\
\infty & \infty\end{array}$ & 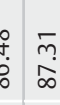 & 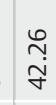 & $\underset{m}{\stackrel{\infty}{i}}$ & $\begin{array}{l}\stackrel{\omega}{m} \\
\ddot{n}\end{array}$ & $\begin{array}{c}\bar{y} \\
\infty \\
\infty \\
\infty\end{array}$ & $\hat{n}$ & $\begin{array}{l}\text { Lी } \\
\text { gं }\end{array}$ & $\begin{array}{l}\text { fó } \\
\text { fं }\end{array}$ & & 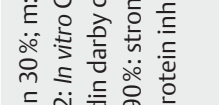 \\
\hline ฉี & a & $E$ & $\sigma$ & 0 & $a$ & $a$ & 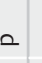 & $=E$ & $\sigma$ & $\sigma$ & $a$ & $\sigma=$ & $=0$ & $a$ & $a$ & $E$ & $E$ & $a$ & $\sigma$ & $\sigma$ & ○ & \\
\hline$\sum$ & 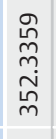 & 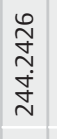 & $\begin{array}{l}\underset{N}{\tilde{J}} \\
\underset{\infty}{\sim} \\
\underset{\sim}{N}\end{array}$ & 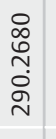 & $\begin{array}{l}\stackrel{n}{n} \\
\stackrel{n}{n} \\
\dot{D} \\
m\end{array}$ & 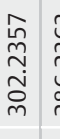 & 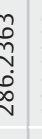 & 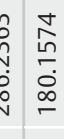 & 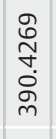 & 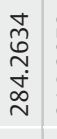 & $\begin{array}{l}\hat{n} \\
\hat{m} \\
\emptyset \\
\underline{m} \\
\underline{m}\end{array}$ & 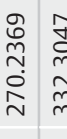 & 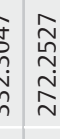 & 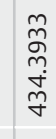 & 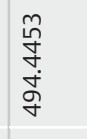 & 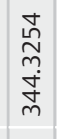 & 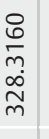 & 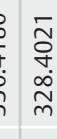 & $\begin{array}{l}\stackrel{0}{ } \\
\underset{\sim}{\infty} \\
\infty \\
\sim \\
\sim\end{array}$ & 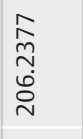 & 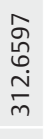 & 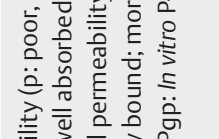 \\
\hline$\vec{\Sigma}$ & $\begin{array}{l}0^{\infty} \\
\stackrel{N}{\mathbf{N}} \\
\mathbf{N} \\
\mathbf{U}\end{array}$ & 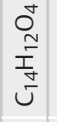 & 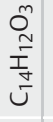 & 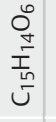 & 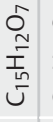 & 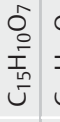 & 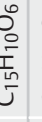 & 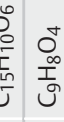 & 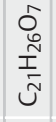 & 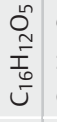 & 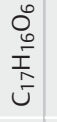 & 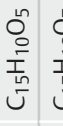 & 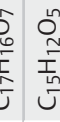 & $\left\{\begin{array}{l}0 \\
N \\
N \\
N\end{array}\right.$ & \begin{tabular}{l}
$\delta$ \\
N \\
Ñ \\
\multirow{N}{N}{}
\end{tabular} & 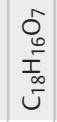 & 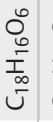 & 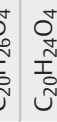 & $\begin{array}{l}O_{\infty}^{+} \\
I^{ \pm} \\
\underline{m} \\
\mathcal{m}\end{array}$ & 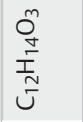 & $\begin{array}{l}O^{+} \\
\text {İ } \\
\text { İ } \\
\text { U. }\end{array}$ & \\
\hline 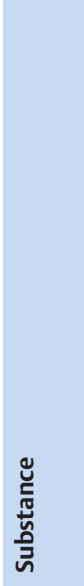 & 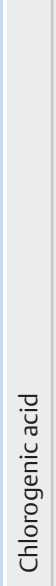 & 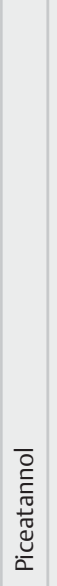 & 离 & 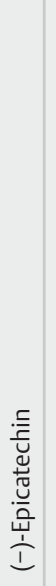 & $\frac{5}{\frac{5}{0}}$ & & 产 & 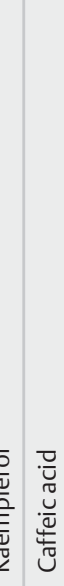 & 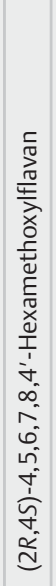 & 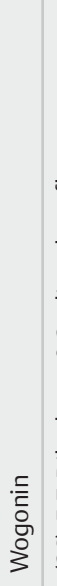 & 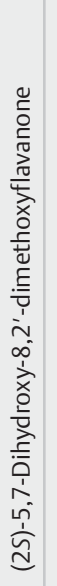 & 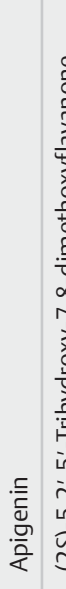 & 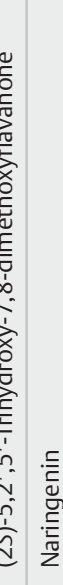 & 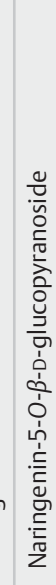 & 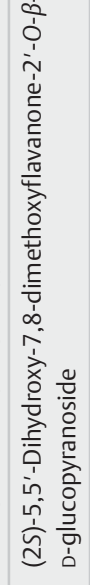 & 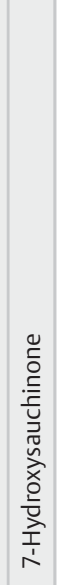 & 亏ั & $\begin{array}{l}\cdot \frac{5}{5} \\
\cdot \frac{\pi}{\pi}\end{array}$ & 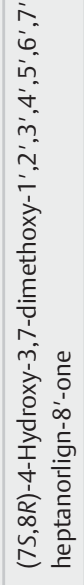 & 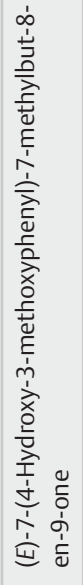 & & 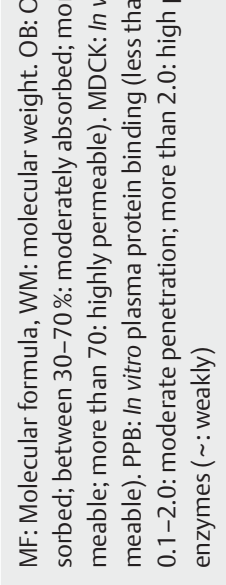 \\
\hline
\end{tabular}


- Table 4 Toxicity features and drug-likeness properties of revised polyphenol compounds with anti-ARG potential.

\begin{tabular}{|c|c|c|c|c|c|}
\hline Substance & Mutagenicity & $\begin{array}{l}\text { Carcinogenity } \\
\text { (mouse) }\end{array}$ & $\begin{array}{l}\text { Carcinogenity } \\
\text { (rat) }\end{array}$ & $\begin{array}{l}\text { hERG inhibi- } \\
\text { tion (risk) }\end{array}$ & $\begin{array}{l}\text { Lipinski's } \\
\text { rule }\end{array}$ \\
\hline Chlorogenic acid & negative & positive & negative & medium & suitable \\
\hline Piceatannol & positive & negative & negative & medium & suitable \\
\hline Resveratrol & positive & negative & negative & medium & suitable \\
\hline (-)-Epicatechin & positive & negative & negative & medium & suitable \\
\hline Taxifolin & positive & negative & positive & medium & suitable \\
\hline Quercetin & positive & negative & positive & medium & suitable \\
\hline Fisetin & positive & negative & positive & medium & suitable \\
\hline Kaempferol & positive & negative & positive & medium & suitable \\
\hline Caffeic acid & positive & negative & positive & medium & suitable \\
\hline$(2 R, 4 S)-4,5,6,7,8,4^{\prime}$-Hexamethoxylflavan & positive & negative & positive & low & suitable \\
\hline Wogonin & positive & negative & positive & medium & suitable \\
\hline (2S)-5,7-Dihydroxy-8,2'-dimethoxyflavanone & negative & negative & positive & medium & suitable \\
\hline Apigenin & positive & positive & positive & medium & suitable \\
\hline (2S)-5,2',5'-Trihydroxy-7,8-dimethoxyflavanone & negative & negative & positive & low & suitable \\
\hline Naringenin & positive & negative & positive & medium & suitable \\
\hline Naringenin-5-O- $\beta$-D-glucopyranoside & positive & negative & negative & high & suitable \\
\hline $\begin{array}{l}\text { ( } 2 S)-5,5^{\prime} \text {-Dihydroxy-7,8-dimethoxyflavanone-2'-O- } \beta \text {-D- } \\
\text { glucopyranoside }\end{array}$ & negative & negative & negative & - & violated \\
\hline 7-Hydroxysauchinone & negative & negative & negative & low & suitable \\
\hline Sauchinone & positive & negative & positive & low & suitable \\
\hline meso-Dihydroguaiaretic acid & negative & negative & negative & medium & suitable \\
\hline Guaiacin & positive & negative & negative & medium & suitable \\
\hline $\begin{array}{l}(75,8 R) \text {-4-Hydroxy-3,7-dimethoxy-1', } 2^{\prime}, 3^{\prime}, 4^{\prime}, 5^{\prime}, 6^{\prime}, 7^{\prime}- \\
\text { heptanorlign-8'-one }\end{array}$ & positive & negative & positive & low & suitable \\
\hline (E)-7-(4-Hydroxy-3-methoxyphenyl)-7-methylbut-8-en-9-one & positive & negative & positive & low & suitable \\
\hline Licarin A & positive & negative & positive & medium & suitable \\
\hline
\end{tabular}

Mutagenicity: based on the Ames test; Carcinogenity: 2-year bioassay in the mouse/rat; hERG: in vitro human ether-a-go-go-related gene channel inhibition; Lipinski's rule: hydrogen bond donors less than 5 , hydrogen bond acceptor less than 10, molecular weight less than 500 Da; CLogP less than 5 (MlogP less than 4.15)

acid was better absorbed than other phenolic substances (the $\mathrm{C}_{\max }$ values reached $4 \mu \mathrm{mol} / \mathrm{L}$ with a $50-\mathrm{mg}$ dose), followed by isoflavones, catechins, flavanones, quercetin glucosides, proanthocyanidins, galloylated tea catechins, and anthocyanins [118]. Additionally, the time to $\mathrm{C}_{\max }$ varied from approximately $1.5 \mathrm{~h}$ to $5.5 \mathrm{~h}$, taking into account the site of intestinal absorption [117].

After absorption, molecules are distributed from plasma to other compartments of the body. In relation to anti-ARG polyphenols, approximately half of them occur in free state in the circulation (weakly bound to plasma proteins) and they can reach several parts of the peripheral system to achieve their potential enzyme inhibition ( $V_{d}$ value). In addition, only two of these anti-ARG polyphenols have the ability to cross the blood-brain barrier, which could result in biological or toxicological effects.

For most of the polyphenols that are absorbed, the plasma concentration quickly decreases. The metabolism mainly occurs in the liver (methylation and/or conjugation with glucuronic acid or sulphate), supported by the metabolism of the kidneys and in- testinal mucosa. Thus, achieving elevated levels of polyphenols in plasma requires repeated ingestion over time. However, catechins, gallic acid, and flavanones seem to have no chance to accumulate, even with sequential administrations. On the other hand, quercetin exhibits a high affinity for plasmatic albumin, which might explain its higher elimination half-life $(24 \mathrm{~h})[115,117]$.

Taking this into consideration, the excretion of polyphenols occurs mainly in urine or feces (especially phenols that are resistant to microflora degradation, such as condensed tannins and those linked to macromolecules) [113], and can be expressed as MDCK cell permeability, which predicts renal excretion ability. In this context, most of the anti-ARG phenolics reviewed present moderate permeability capability, suggesting a moderate to high maintenance of these substances in the organism. Additionally, attention should be paid to those phenolics that are highly bound to plasma proteins due to the risk of toxicity from long-term use and accumulated doses [110]. 
Regarding toxicity ( $\bullet$ Table 4), plant-derived substances have a favourable spectrum in most cases, which is very important during drug development. Only one of the reviewed polyphenols presents a high risk of inhibiting hERG (a gene that encodes a potassium ion channel expressed in the heart and when inhibited can produce a long QT syndrome that results in potentially fatal arrhythmias) [119], although almost all the phenolics presented positive predictions regarding mutagenic or carcinogenic (mouse and/or rat) action. These points are relevant since they can determine the final outcome of new therapeutic approaches.

Concerning the predicted toxicological potential, the dosage must be considered because some effects only appear at higher doses. For this purpose, daily dietary reference intakes of polyphenols are required and are highly desirable, although data are currently insufficiently available to establish how to avoid upper doses with possible toxic effects [120].

Finally, completing the prediction analysis, the drug-likeness investigation of polyphenols with potential activity as ARG inhibitors showed that only one substance violated Lipinki's rule and therefore could not be recommended as an emergent drug in the management of ED.

\section{Concluding Remarks and Perspectives}

The development of new ARG inhibitors represents a very promising strategy in relation to the treatment of diseases caused by the damage involved in the production and function of NO.

The number of potential indications is broad and includes cardiovascular, pulmonary, metabolic, and neurological problems as well as erectile dysfunction and, more recently, cancer therapy since the conversion of L-arginine by ARG is a trigger for tumour promotion and progression.

Synthetic products derived from boronic acid have been extensively studied as modulators of ARG activity due to their polarisability. However, many of these prototypes have an unfavourable toxicological profile, with high potency (subnanomolar range), especially in relation to hepatocytes, which results in them being decharacterised as new inhibitors unless such obstacles are improved by means of structural, molecular, or pharmacotechnical modifications (prodrug and vector-based dosage forms). Furthermore, another issue to be addressed is the inappropriate (oral) pharmacokinetic profile presented by most of the available inhibitors, since in most cases these are substances whose structures are based on amino acids, which easily lose stability (very short half-life) and potency at physiological pH [121].

In addition, given the different expression of ARG 1 and ARG 2 in tissues, and their divergent actions depending on the pathological context, it is interesting that sufficient specific and selective inhibitors of this enzyme are available. According to the literature, specificity has not become a hindrance in relation to this issue, as opposed to selectivity for isoforms. For example, endothelial tissues express the two major isoforms of ARG, however, it is not precisely known what the role of each of these isoforms is in the evolution of $E D$. There remains considerable controversy about the role of the expression of ARG in different conditions like atherosclerosis and other forms of vessel inflammation. For instance, hyperglycaemia of diabetes causes ED via the activation of p38 MAPK, which pro- duces the upregulation of ARG 1 in coronary arteries and the increased expression of ARG 2 in mesenteric arteries [44, 122].

Furthermore, the 3D comparison of ARGs has not presented significant differences (almost totally homologue), with certain portions that are considered critical to enzymatic activity [123]. Indeed, natural products have not presented enough selectivity to inhibit a specific ARG isoform, and the effects of enzyme inhibition in determined vessels cannot be generalised for all vasculatures. There is also growing evidence that ARG expression and activation can be detrimental or beneficial depending on the biological context that is analysed. For this reason, it is not yet completely understood which ARG isoform should be targeted in order to achieve better outcomes [26, 44, 84].

Thus, further in-depth studies and investigations are required regarding the consequences of ARG inhibition on essential functions of the organism, such as the processes of neuronal development, healing, and angiogenesis. This is due to the fact that the synthesis of proline and polyamines could be blocked, as well as the possibility of a possible disruption of the urea cycle in the liver. It seems contradictory that studies regarding ARG inhibition do not report significant toxic effects on the urea cycle, possibly because of high levels of ARG expression in the liver (up to one thousand times more than normal) compared to the endothelium, therefore making it unlikely that the suppression of this function can be achieved by therapeutically viable doses of the inhibitor [6, 124]. From another point of view, human ARG deficiency seems to be a disorder that is effectively treated, and acute hyperammonaemia does not represent a great risk for most patients [123].

Moreover, long-term studies of ARG inhibition have failed to observe a compensatory upregulation of the enzyme $[26,125]$. Therapies utilising ARG inhibitors in systemic doses are used in the treatment of parasitic diseases without significant adverse effects [44].

A growing number of studies have demonstrated the role of ARG inhibition in functions involving cell growth and tissue repair, and such studies have produced interesting findings. In keeping with this, studies have reported that blocking the activity of ARG can prevent the reduction of angiogenesis (the maintenance of NO-induced VEGF expression), induce vascular repair in experimental ischaemic retinopathy (normalisation of NOS function and reduction of superoxide production) [126], and promote wound healing in mice (correlated with NO formation followed by reepithelialisation, since NO itself can mediate collagen synthesis) [127]. Otherwise, ARG 2 and ARG 1 knockout animals have shown conflicting results. The ARG 2 group presented diminished fertility in the males, while the ARG 1 group presented a more critical phenothype due to hyperammonaemia, which resulted in death within 10 days [123]. Thus, the extent of the effects generated by ARG inhibition in vivo should be better defined, even though it is probable that therapeutic doses do not cause such dramatic effects, as previously mentioned.

In the context of the study of ARG and the development of new ARG inhibitors with a focus on higher NO rates, plants are a very versatile source, given the richness of the substances that they produce (generally of low toxicity and great abundance), which can act as direct inhibitors or serve as a molecular model for the 
synthesis of semisynthetic products or products that are fully developed in the laboratory.

The data presented in this article highlights important evidence that emphasises the role of plants as a reliable source of new therapeutic agents. Promising results have been obtained in very complex pathologies, which is reinforced by the fact that from the 1940 s to 2014 , of the 175 molecules that were used to treat cancer, 85 (49\%) were natural products or direct derivatives of them [33].

On the other hand, the identification of polyphenol metabolites is still a challenge requiring more in-depth studies, taking into account the innumerable factors that can influence their production, as well as the need to standardise the methodologies of identification and quantification of these compounds. In addition, efforts should be made to achieve the lower doses attained in clinically significant biological fluids and tissues to produce an effect over a suitable period of time [128]. It is also necessary to evaluate the new chemical species formed in vivo, compared to their original structures, to confirm either the maintenance of beneficial effects or the creation of toxic mechanisms [129].

Nevertheless, it remains unclear how after the absorption and metabolisation of polyphenols (which are mostly found in systemic circulation as glucuronidated forms following oral administration), biological activity continues occurring, since pharmacophoric sites (hydroxyl groups) are not available. Some studies have suggested that this activity might be related to a deconjugation reaction at the cellular level (this requires further investigation) or that the metabolites are still active in conjugated form [130]. Regarding the last hypothesis, quercetin glucuronides are reported to prevent cardiovascular diseases [131]. Similarly, quercetin-3'-sulfate and isorhamnetin-3-glucuronide ( $10 \mu \mathrm{mol} / \mathrm{L})$ may prevent ED by an antioxidant mechanism, and quercetin-3-glucuronide $(1 \mu \mathrm{mol} / \mathrm{L})$ may prevent vascular impairment induced by endothelin-1 [132]. Furthermore, the stilbene derivative piceatannol appears to be more active as an ARG inhibitor compared to its precursor resveratrol, and for this reason it is more plausible to be applied in future clinical trials.

Thus, taking into account the foregoing, a new horizon of mechanisms related to the direct and indirect inhibition of ARG is coming into view. From another point of view, this enzyme has also become a valuable biochemical tool as a serum marker for serious diseases such as cancer.

In summary, there is substantial evidence to show the therapeutic potential of ARG inhibition in relation to the damage associated with the low bioavailability of NO. Consequently, this enzyme is highly attractive in terms of the research and development of new drugs, since such treatments can help to correct both ED and dysfunction of the adjacent smooth muscle tissue. It is important to note that secondary metabolites derived from plants with propriety to polyphenols are molecules of interest for the clinical application of ARG inhibition in relation to ED. Finally, the information compiled in this article will underpin future investigations regarding the anti-ARG activity of substances isolated from plants in order to produce reproducible and clinically relevant data in this field.

\section{Acknowledgements}

The authors are grateful to Dr. Sean Stroud for revising the English in this text.

\section{Conflict of Interest}

The authors declare that they have no conflicts of interest.

\section{References}

[1] Berkowitz DE, White R, Li D, Minhas KM, Cernetich A, Kim S, Burke S, Shoukas AA, Nyhan D, Champion HC, Hare JM. Arginase reciprocally regulates nitric oxide synthase activity and contributes to endothelial dysfunction in aging blood vessels. Circulation 2003; 108: 2000-2006

[2] Durante W, Johnson FK, Johnson RA. Arginase: a critical role regulator of nitric oxide synthesis and vascular function. Clin Exp Pharmacol Physiol 2007; 34: 906-911

[3] Meurs H, Maarsingh H, Zaagsma J. Arginase and asthma: novel insights into nitric oxide homeostasis and airway hyperresponsiveness. Trends Pharmacol Sci 2003; 24: 450-455

[4] Romero M], Platt DH, Tawfik HE, Labazi M, El-Remessy AB, Bartoli M, Caldwell RB, Caldwell RW. Diabetes-induced coronary vascular dysfunction involves increased arginase activity. Circ Res 2008; 102: 95-102

[5] Ryoo S, Gupta G, Benjo A, Lim HK, Camara A, Sikka G, Lim HK, Sohi J, Santhanam L, Soucy K, Tuday E, Baraban E, Ilies M, Gerstenblith G, Nyhan D, Shoukas A, Christianson DW, Alp NJ, Champion HC, Huso D, Berkowitz DE. Endothelial arginase II: a novel target for the treatment of atherosclerosis. Circ Res 2008; 102: 923-932

[6] Schade D, Kotthaus J, Clement B. Modulating the NO generating system from a medicinal chemistry perspective: current trends and therapeutic options in cardiovascular disease. Pharmacol Ther 2010; 126: 279-300

[7] You H, Gao T, Cooper TK, Morris SM jr., Awad AS. Arginase inhibition mediates renal tissue protection in diabetic nephropathy by a nitric oxide synthase 3-dependent mechanism. Kidney Int 2013; 84: 1189-1197

[8] El-Bassossy HM, El-Fawal R, Fahmy A. Arginase inhibition alleviates hypertension associated with diabetes: effect on endothelial dependent relaxation and NO production. Vascul Pharmacol 2012; 57: 194-200

[9] Shemyakin A, Kövamees O, Rafnsson A, Böhm F, Svenarud P, Settergren $M$, Jung C, Pernow J. Arginase inhibition improves endothelial function in patients with coronary artery disease and type 2 diabetes mellitus. Circulation 2012; 126: 2943-2950

[10] Pacher P, Beckman JS, Liaudet L. Nitric oxide and peroxynitrite in health and disease. Physiol Rev 2007; 87: 315-424

[11] Steppan J, Nyhan D, Berkowitz DE. Development of novel arginase inhibitors for therapy of endothelial dysfunction. Front Immunol 2013; 4: 278

[12] Schmitt CA, Dirsch VM. Modulation of endothelial nitric oxide by plantderived products. Nitric Oxide 2009; 21: 77-91

[13] Cai H, Harrison DG. Endothelial dysfunction in cardiovascular diseases: the role of oxidant stress. Circ Res 2000; 87: 840-844

[14] Félétou M, Vanhoutte PM. Endothelial dysfunction: a multifaceted disorder. Am J Physiol Heart Circ Physiol 2006; 291: H985-H1002

[15] Vanhoutte PM, Shimokawa H, Feletou M, Tang EHC. Endothelial dysfunction and vascular disease - a 30th anniversary update. Acta Physiol (Oxf) 2017; 219: 22-96

[16] Versari D, Daghini E, Virdis A, Ghiadoni L, Taddei S. Endothelial dysfunction as a target for prevention of cardiovascular disease. Diabetes Care 2009; 32: S314-\$321

[17] Akinyemi A], Oboh G, Ademiluyi AO, Boligon AA, Athayde ML. Effect of two ginger varieties on arginase activity in hypercholesterolemic rats. J Acupunct Meridian Stud 2016; 9: 80-87 
[18] Chung JH, Moon J, Lee YS, Chung HK, Lee SM, Shin MJ. Arginase inhibition restores endothelial function in diet-induced obesity. Biochem Biophys Res Commun 2014; 451: 179-183

[19] Colwell JA, Lopes-Virella M, Halushka PV. Pathogenesis of atherosclerosis in diabetes mellitus. Diabetes Care 1981; 4: 121-133

[20] Cooke JP, Dzau J, Creager A. Endothelial dysfunction in hypercholesterolemia is corrected by L-arginine. Basic Res Cardiol 1991; 86: 173-181

[21] Lüscher TF. Heterogeneity of endothelial dysfunction in hypertension. Eur Heart J 1992; 13: 50-55

[22] Flavahan NA. Atherosclerosis or lipoprotein-induced endothelial dysfunction: potential mechanisms underlying reduction in EDRF/nitric oxide activity. Circulation 1992; 85: 1927-1938

[23] Todoki K, Okabe E, Kiyose T, Sekishita T, Ito H. Oxygen free radical-mediated selective endothelial dysfunction in isolated coronary artery. Am J Physiol 1992; 262: H806-H812

[24] Schini-Kerth VB, Etienne-Selloum N, Chataigneau T, Auger C. Vascular protection by natural product-derived polyhenols: in vitro and in vivo evidence. Planta Med 2011; 77: 1161-1167

[25] Ivanenkov YA, Chufarova NV. Small-molecule arginase inhibitors. Pharm Pat Anal 2014; 3: 65-85

[26] Pernow J, Jung C. Arginase as a potential target in the treatment of cardiovascular disease: reversal of arginine steal? Cardiovasc Res 2013; 98 : 334-343

[27] Girard-Thernier C, Pham TN, Demougeot C. The promise of plant-derived substances as inhibitors of arginase. Mini Rev Med Chem 2015; 15: 798-808

[28] Romero M], Platt DH, Tawfik HE, Labazi M, El-Remessy AB, Bartoli M, Caldwell RB, Caldwell RW. Diabetes-induced coronary vascular dysfunction involves increased arginase activity. Circ Res 2008; 102: 95-102

[29] Schnorr O, Brossette T, Momma TY, Kleinbongard P, Keen CL, Schroeter $\mathrm{H}$, Sies $\mathrm{H}$. Cocoa flavanols lower vascular arginase activity in human endothelial cells in vitro and in erythrocytes in vivo. Arch Biochem Biophys 2008; 476: 211-215

[30] Yi B, Nguyen MC, Won MH, Kim YM, Ryoo S. Arginase inhibitor 2, 3, 5, 4'tetrahydroxystilbene-2-O- $\beta$-D-glucoside activates endothelial nitric oxide synthase and improves vascular function. Planta Med 2016; 83: 210-216

[31] Huynh NN, Harris EE, Chin-Dusting JFP, Andrews KL. The vascular effects of different arginase inhibitors in rat isolated aorta and mesenteric arteries. Br J Pharmacol 2009; 156: 84-93

[32] Minozzo BR, Lemes BM, Justo AS, Lara JE, Petry VEK, Fernandes D, Belló C, Vellosa JCR, Campagnoli EB, Nunes OC, Kitagawa RR, Avula B, Khan IA, Beltrame FL. Anti-ulcer mechanisms of polyphenols extract of Euphorbia umbellata (Pax) Bruyns (Euphorbiaceae). J Ethnopharmacol 2016; 191: 29-40

[33] Newman DJ, Cragg GM. Natural products as sources of new drugs from 1981 to 2014. J Nat Prod 2016; 79: 629-661

[34] Bordage S, Pham TN, Zedet A, Gugglielmetti AS, Nappey M, Demougeot $C$, Girard Thernier C. Investigation of mammal arginase inhibitory properties of natural ubiquitous polyphenols by using an optimized colorimetric microplate assay. Planta Med 2017; 83: 647-653

[35] Dal-Ros S, Bronner C, Auger C, Schini-Kerth VB. Red wine polyphenols improve an established aging-related endothelial dysfunction in the mesenteric artery of middle-aged rats: role of oxidative stress. Biochem Biophys Res Commun 2012; 419: 381-387

[36] Kim SW, Cuong TD, Hung TM, Ryoo S, Lee JH, Min BS. Arginase II inhibitory activity of flavonoid compounds from Scutellaria indica. Arch Pharm Res 2013; 26: 922-926

[37] Li LC, Kan LD. Traditional Chinese medicine for pulmonary fibrosis therapy: Progress and future prospects. J Ethnopharmacol 2017; 198: 45-63

[38] Oboh G, Ademiluyi AO, Ademosun AO, Olasehinde TA, Oyeleye SI, Boligon AA, Athayde M. Phenolic extract from Moringa oleifera leaves in- hibits key enzymes linked to erectile dysfunction and oxidative stress in rats' penile tissues. Biochem Res Int 2015; 2015: 175950

[39] Di Costanzo L, Sabio G, Mora A, Rodriguez PC, Ochoa AC, Centeno F, Christianson DW. Crystal structure of human arginase I at 1.29-A resolution and exploration of inhibition in the immune response. Proc Natl Acad Sci U S A 2005; 102: 13058-13063

[40] Cama E, Pethe S, Boucher JL, Han S, Emig FA, Ash DE, Viola RE, Mansuy D, Christianson DW. Inhibitor coordination interactions in the binuclear manganese cluster of arginase. Biochemistry 2004; 43: 8987-8999

[41] Boucher JL, Moali C, Tenu JP. Nitric oxide biosynthesis, nitric oxide synthase inhibitors and arginase competition for L-arginine utilization. Cell Mol Life Sci 1999; 55: 1015-1028

[42] Cama E, Colleluori DM, Emig FA, Shin H, Kim SW, Kim NN, Traish AM, Ash DE, Christianson DW. Human arginase II: crystal structure and physiological role in male and female sexual arousal. Biochemistry 2003; 42: 8445-8451

[43] Zamecka E, Porembska Z. Five forms of arginase in human tissues. Biochem Med Metab Biol 1988; 39: 258-266

[44] Caldwell RB, Toque HA, Narayanan SP, Caldwell RW. Arginase: an old enzyme with new tricks. Trends Pharmacol Sci 2015; 36: 395-405

[45] Chen B, Calvert AE, Meng X, Nelin LD. Pharmacologic agents elevating camp prevent arginase II expression and proliferation of pulmonary artery smooth muscle cells. Am J Respir Cell Mol Biol 2012; 47: 218-226

[46] Durante W. Role of arginase in vessel wall remodeling. Front Immunol 2013; 13: 111

[47] Jenkinson CP, Grody WW, Cederbaum SD. Comparative properties of arginases. Comp Biochem Physiol 1996; 114: 107-132

[48] Konarska L, Tomaszewski L, Colombo JP, Terheggen HG. Human salivary arginase and its deficiency in argininaemia. J Clin Chem Clin Biochem 1985; 23: 337-342

[49] Morris SM jr., Bhamidipati D, Kepka-Lenhart D. Human type II arginase: sequence analysis and tissue-specific expression. Gene 1997; 193: 157161

[50] Ryoo S, Bhunia A, Chang F, Shoukas A, Berkowitz DE, Romer LH. OxLDLdependent activation of arginase II is dependent on the LOX-1 receptor and downstream RhoA signaling. Atherosclerosis 2011; 214: 279-287

[51] Shatanawi A, Lemtalsi T, Yao L, Patel C, Caldwell RB, Caldwell RW. Angiotensin II limits NO production by upregulating arginase through a p38 MAPK-ATF-2 pathway. Eur J Pharmacol 2015; 5: 106-114

[52] Waddington SN, Tam FWK, Cook HT, Cattell V. Arginase activity is modulated by IL-4 and HOArg in nephritic glomeruli and mesangial cells. Am J Physiol 1998; 274: F473-F480

[53] Adeva MM, Souto G, Blanco N, Donapetry C. Ammonium metabolism in humans. Metabolism 2012; 61: 1495-1511

[54] Gotoh T, Araki M, Mori M. Chromosomal localization of the human arginase II gene and tissue distribution of its mRNA. Biochem Biophys Res Commun 1997; 233: 487-491

[55] Maarsingh H, Zaagsma J, Meurs H. Arginase: a key enzyme in the pathophysiology of allergic asthma opening novel therapeutic perspectives. $\mathrm{Br}$ J Pharmacol 2009; 158: 652-664

[56] Sparkers RS, Dizikes G], Klisak I, Grody WW, Mohandas T, Heinzmann C, Zollman S, Lusis AJ, Cederbaum SD. The gene for human liver arginase (ARG1) is assigned to chromosome band 6q23. Am J Hum Genet 1986; 39: 186-193

[57] Chen F, Lucas R, Fulton D. The subcellular compartmentalization of arginine metabolizing enzymes and their role in endothelial dysfunction. Front Immunol 2013; 9: 184

[58] André C, Herlem G, Ghardi T, Guillaume YC. A new arginase enzymatic reactor: development and application for the research of plant-derived inhibitors. J Pharm Biomed Anal 2011; 55: 48-53

[59] We LH, Wu G, Morris SM jr., Ignarro L]. Elevated arginase I expression in rat aortic smooth muscle cell increases cell proliferation. Proc Natl Acad Sci U S A 2001; 98: 9260-9264 
[60] Yoon J, Ryoo S. Arginase inhibition reduces interleukin- $\beta$-stimulated vascular smooth muscle cell proliferation by increasing nitric oxide synthase-dependent nitric oxide production. Biochem Biophys Res Commun 2013; 435: 428-433

[61] Kim JH, Bugaj LJ, Oh Y], Bivalacqua T], Ryoo S, Soucy KG, Santhanam L, Webb A, Camara A, Sikka G, Nyhan D, Shoukas AA, Ilies M, Christianson DW, Champion HC, Berkowitz DE. Arginase inhibition restores NOS coupling and reverses endothelial dysfunction and vascular stiffness in old rats. J Appl Physiol 2009; 107: 1249-1257

[62] Pautz A, Art J, Hahn S, Nowag S, Voss C, Kleinert H. Regulation of the expression of inducible nitric oxide synthase. Nitric Oxide 2010; 23: 7593

[63] Morris SM jr. Recent advances in arginine metabolism: roles and regulation of the arginases. Br J Pharmacol 2009; 157: 922-930

[64] Louis CA, Mody V, Henry WL jr., Reichner JS, Albina JE. Regulation of arginase isoforms I and II by IL-4 in cultured murine peritoneal macrophages. Am J Physiol 1999; 276: R237-R242

[65] Woo A, Min B, Ryoo S. Piceatannol-3'-O- $\beta$-D-glucopyranoside as an active component of rhubarb activates endothelial nitric oxide synthase through inhibition of arginase activity. Exp Mol Med 2010; 42: 524-532

[66] El Kasmi KC, Qualls JE, Pesce JT, Smith AM, Thompson RW, Henao-Tamayo M, Basaraba RJ, König T, Schleicher U, Koo MS, Kaplan G, Fitzgerald K, Tuomanen El, Orme IM, Kanneganti TD, Bodgan C, Wynn TA, Murray PJ. Toll-like receptor-induced arginase 1 in macrophages thwarts effective immunity against intracellular pathogens. Nat Immunol 2008; 9: 1399-1406

[67] Lucas R, Yang G, Gorshkov BA, Zemskov EA, Sridhar S, Umapathy NS, Jezierska-Drutel A, Alieva IB, Leustik M, Hossain H, Fischer B, Catravas JD, Verin AD, Pittet JF, Caldwell RB, Mitchell TJ, Cederbaum SD, Fulton DJ, Matthay MA, Caldwell RW, Romero MJ, Chakraborty T. Protein kinase C$\alpha$ and arginase I mediate pneumolysin-induced pulmonary endothelial hyperpermeability. Am J Respir Cell Mol Biol 2012; 47: 445-453

[68] Wang C, Chen H, Luo H, Zhu L, Zhao Y, Tian H, Wang R, Shang P, Zhao Y. Microgravity activates p38 MAPK-C/EBP $\beta$ pathway to regulate the expression of arginase and inflammatory cytokines in macrophages. Inflamm Res 2015; 64: 303-311

[69] Corraliza IM, Modolell M, Ferber E, Soler G. Involvement of protein kinase $A$ in the induction of arginase in murine bone marrow-derived macrophages. Biochim Biophys Acta 1997; 1334: 123-128

[70] Chang Cl, Zoghi B, Liao J, Kuo L. The involvement of tyrosine kinases, cyclic AMP/protein kinase A, and p38 mitogen-activated protein kinase in IL-13-mediated arginase I induction in macrophages: its implications in IL-13-inhibited nitric oxide production. J Immunol 2000; 165: 21342141

[71] Nelin LD, Chicoine LG, Reber KM, English BK, Young TL, Liu Y. Cytokineinduced endothelial arginase expression is dependent on epidermal growth factor receptor. Am J Respir Cell Mol Biol 2005; 33: 394-401

[72] Chem Gonzalez-Garrido JA, Olivares-Corichi IM, Tovar-Rodriguez JM, Hernández-Santana NA, Méndez-Bolaina E, Ceballos-Reyes GM, GarcíaSánchez JR. Influence of the AT2 receptor on the L-arginine-nitric oxide pathway and effects of (-)-epicatechin on HUVECs from women with preeclampsia. J Hum Hypertens 2013; 27: 355-361

[73] Lundberg JO, Gladwin MT, Weitzberg E. Strategies to increase nitric oxide signaling in cardiovascular disease. Nat Rev Drug Discov 2015; 14 : 623-641

[74] Li H, Förstermann U. Uncoupling of endothelial NO synthase in atherosclerosis and vascular disease. Curr Opin Pharmacol 2013; 13: 161-167

[75] Frombaum M, Le Clanche S, Bonnefont-Rousselot D, Borderie D. Antioxidant effects of resveratrol and other stilbene derivatives on oxidative stress and - NO bioavailability: potential benefits to cardiovascular diseases. Biochimie 2012; 94: 269-276

[76] Mitjavila MT, Moreno J]. The effects of polyphenols on oxidative stress and the arachidonic acid cascade. Implications for the prevention/treat- ment of high prevalence diseases. Biochem Pharmacol 2012; 84: 1113 1122

[77] Pereira TMC, Pimenta FS, Porto ML, Baldo MP, Campagnaro BP, Gava AL, Meyrelles SS, Vasquez EC. Coadjuvants in the diabetic complications: nutraceuticals and drugs with pleiotropic effects. Int J Mol Sci 2016; 17: $1-24$

[78] Suganya S, Bhakkiyalakshmi E, Sarada DVL, Ramkumar KM. Reversibility of endothelial dysfunction in diabetes: role of polyphenols. $\mathrm{Br} J$ Nutr 2016; 116: 223-246

[79] Yoon J, Park M, Lee JH, Min BS, Ryoo S. Endothelial nitric oxide synthase activation through obacunone-dependent arginase inhibition restored impaired endothelial function in ApoE-null mice. Vascul Pharmacol 2014; 60: 102-109

[80] Hardy TA, May JM. Coordinate regulation of L-arginine uptake and nitric oxide synthase activity in cultured endothelial cells. Free Radic Biol Med 2002; 32: 122-131

[81] Sahach VF, Baziliuk OV, Kotsiuruba AV, Buzhanevich OM. Disorders of endothelium-dependent vascular reactions and of the arginase and NO-synthase pathways of L-arginine metabolism in arterial hypertension. Fiziol Zh 2000; 46: 3-13

[82] Demougeot C, Prigent-Tessier A, Marie C, Berthelot A. Arginase inhibition reduces endothelial dysfunction and blood pressure rising in spontaneously hypertensive rats. J Hypertens 2005; 23: 971-978

[83] White AR, Ryoo LD, Champion HC, Steppan J, Wang D, Nyhan D, Shoukas AA, Hare JM, Berkowitz DE. Knockdown of arginase I restores NO signaling in the vasculature of old rats. Hypertension 2006; 47: 245-251

[84] Abdelkawy KS, Lack K, Elbarbry F. Pharmacokinetics and pharmacodynamics of promising arginase inhibitors. Eur J Drug Metab Pharmacokinet 2016. doi:10.1007/s13318-016-0381-y

[85] Chen D, Frezza M, Schmitt S, Kanwar J, Dou QP. Bortezomib as the first proteasome inhibitor anticancer drug: current status and future perspectives. Curr Cancer Drug Targets 2011; 11: 239-253

[86] Newman DJ, Cragg GM. Natural products as sources of new drugs over the 30 years from 1981 to 2010. J Nat Prod 2012; 75: 311-335

[87] Akanni OO, Owumi SE, Adaramoye OA. In vitro studies to assess the antioxidative, radical scavenging and arginase inhibitory potentials of extracts from Artocarpus altilis, Ficus exasperate and Kigelia africana. Asian Pac J Trop Biomed 2014; 4: S492-S499

[88] Nikolić ], Cvetković T, Sokolović D. Role of quercetin on hepatic urea production in acute renal failure. Ren Fail 2003; 25: 149-155

[89] Duffy CF, Killeen GF, Connolly CD, Power RF. Effects of dietary supplementation with Yucca schidigera Roezl ex Ortgies and its saponin and non-saponin fractions on rat metabolism. J Agric Food Chem 2001; 49: 3408-3413

[90] Shin W, Cuong TD, Lee JH, Min B, Jeon BH, Lim HK, Ryoo S. Arginase inhibition by ethylacetate extract of Caesalpinia sappan lignum contributes to activation of endothelial nitric oxide synthase. Korean J Physiol Pharmacol 2011; 15: 123-128

[91] Shin W, Yoon J, Oh GT, Ryoo S. Korean red ginseng inhibits arginase and contributes to endothelium-dependent vasorelaxation through endothelial nitric oxide synthase coupling. J Ginseng Res 2013; 37: 64-73

[92] Choi K, Yoon J, Lim HK, Ryoo S. Korean red ginseng water extract restores impaired endothelial function by inhibiting arginase activity in aged mice. Korean J Physiol Pharmacol 2014; 18: 95-101

[93] Caldwell RB, Toque HA, Narayanan SP, Caldwell RW. Arginase: an old enzyme with new tricks. Trends Pharmacol Sci 2015; 36: 396-405

[94] Reis MBG, Manjolin LC, Maquiaveli CC, Santos-Filho OA, Silva ER. Inhibition of Leishmania (Leishmania) amazonensis and rat arginases by green tea EGCG, (+)-catechin and (-)-epicatechin: a comparative structural analysis of enzyme-inhibitor interactions. PLoS One 2013; 8: 1-9

[95] Lim C], Cuong TD, Hung TM, Ryoo S, Lee JH, Kim EH, Woo MH, Choi JS, Min BS. Arginase II inhibitory activity of phenolic compounds from Saururus chinensis. Bull Korean Chem Soc 2012; 33: 3079-3082 
[96] Hwang HM, Lee JH, Min BS, Jeon BH, Hoe KL, Kim YM, Ryoo S. A novel arginase inhibitor derived from Scutellavia indica restored endothelial function in ApoE-null mice fed a high-cholesterol diet. J Pharmacol Exp Ther 2015; 355: 57-65

[97] Tang YL, Chan SW. A review of the pharmacological effects of piceatannol on cardiovascular diseases. Phytother Res 2014; 28: 1581-1588

[98] Frombaum M, Therond P, Djelidi R, Beaudeux JL, Bonnefont-Rousselot $\mathrm{D}$, Borderie $\mathrm{D}$. Piceatannol is more effective than resveratrol in restoring endothelial cell dimethylarginine dimethylaminohydrolase expression and activity after high-glucose oxidative stress. Free Radical Res 2011; 45: 293-302

[99] Woo A, Shin W, Cuong TD, Min B, Lee JH, Jeon BH, Ryoo S. Arginase inhibition by piceatannol-3'-O- $\beta$-D-glucopyranoside improves endothelial dysfunction via activation of endothelial nitric oxide synthase in ApoE-null mice fed a high-cholesterol diet. Int J Mol Med 2013; 31: $801-810$

[100] Nguyen MC, Ryoo S. Intravenous administration of piceatannol, an arginase inhibitor, improves endothelial dysfunction in aged mice. Korean J Physiol Pharmacol 2017; 21: 83-90

[101] Joe Y, Zheng M, Kim HJ, Kim S, Uddin J, Park C, Ryu DG, Kang SS, Ryoo S, Ryter SW, Chang KC, Chung HT. Salvianolic acid B exerts vasoprotective effects through the modulation of heme oxygenase- 1 and arginase activities. J Pharmacol Exp Ther 2012; 341: 850-858

[102] García-Niño WR, Zazueta C. Ellagic acid: pharmacological activities and molecular mechanisms involved in liver protection. Pharmacol Res 2015; 97: 84-103

[103] Hernández-Trejo M, Montoya-Estrada A, Torres-Ramos Y, EspejelNúñez A, Guzmán-Grenfell A, Morales-Hernández R, Tolentino-Dolores $\mathrm{M}$, Laresgoiti-Servitje $\mathrm{E}$. Oxidative stress biomarkers and their relationship with cytokine concentrations in overweight/obese pregnant women and their neonates. BMC Immunol 2017; 18: 3

[104] Hussein RH, Khalifa FK. The protective role of ellagitannins flavonoids pretreatment against $\mathrm{N}$-nitrosodiethylamine induced-hepatocellular carcinoma. Saudi J Biol Sci 2014; 21: 589-596

[105] Stolarczyk M, Piwowarski JP, Granica S, Stefańska S, Naruszewicz M, Kiss AK. Extracts from Epilobium sp. herbs, their components and gut microbiota metabolites of Epilobium ellagitannins, urolithins, inhibit hormone-dependent prostate cancer Cells- (LNCaP) proliferation and PSA secretion. Phytother Res 2013; 27: 1842-1848

[106] Cerdá B, Llorach R, Cerón J], Espín JC, Tomás-Barberán FA. Evaluation of the bioavailability and metabolism in the rat of punicalagin, and antioxidant polyphenol from pomegranate juice. Eur J Nutr 2003; 42: 18-28

[107] Landete JM. Ellagitannins, ellagic acid and their derived metabolites: a review about source, metabolism, functions and health. Food Res Int 2011; 44: 1150-1160

[108] Engler MB, Engler MM, Chen CY, Malloy M], Browne A, Chiu EY, Kwak HK, Milbury P, Paul SM, Blumberg J, Mietus-Snyder ML. Flavonoid-rich dark chocolate improves endothelial function and increases plasma epicatechin concentrations in healthy adults. J Am Coll Nutr 2004; 23: 197-204

[109] Schroeter H, Heiss C, Balzer ], Kleinbongard P, Keen CL, Hollenberg NK, Sies H, Kwik-Uribe C, Schmitz HH, Kelm M. (-)-Epicatechin mediates beneficial effects of flavanol-rich cocoa on vascular function in humans. Proc Natl Acad Sci U S A 2006; 103: 1024-1029

[110] Zhang S, Li X, Yang X. Drug-likeness prediction of chemical constituents isolated from Chinese materia medica Ciwujia. J Ethnopharmacol 2017; 198: 131-138

[111] Egert S, Wolffram S, Bosy-Westphal A, Boesch-Saadatmandi C, Wagner AE, Frank J, Rimbach G, Mueller MJ. Daily quercetin supplementation dose-dependently increases plasma quercetin concentrations in healthy humans. J Nutr 2008; 138: 1615-1621
[112] Schramm DD, Karim M, Schrader HR, Holt RR, Kirkpatrick N], Polagruto JA, Ensunsa JL, Schmitz HH, Keen CL. Food effects on the absorption and pharmacokinetics of cocoa flavanols. Life Sci 2003; 73: 857-869

[113] Bravo L. Polyphenols: chemistry, dietary sources, metabolism, and nutritional significance. Nutr Res 1998; 56: 317-333

[114] Ozdal T, Capanoglu E, Altay F. A review on protein-phenolic interactions and associated changes. Food Res Int 2013; 51: 954-970

[115] Scalbert A, Williamson G. Dietary intake and bioavailability of polyphenols. J Nutri 2000; 130: 2073S-2085S

[116] Piskula MK, Terao J. Quercetin's solubility affects its accumulation in rat plasma after oral administration. J Agric Food Chem 1998; 46: 4313-4317

[117] Manach C, Williamson G, Morand C, Scalbert A, Rémésy C. Bioavailability and bioefficacy of polyphenols in humans. I. Review of 97 bioavailability studies 1-3. Am J Clin Nutr 2005; 81: 230S-242S

[118] Jakobek L. Interactions of polyphenols with carbohydrates, lipids and proteins. Food Chem 2015; 175: 556-567

[119] Sanguinetti MC, Tristani-Firouzi M. Review article hERG potassium channels and cardic arrhythmia. Nature 2006; 440: 463-469

[120] Williamson G, Holst B. Dietary reference intake (DRI) value for dietary polyphenols: are we heading in the right direction? Br J Nutr 2008; 99: S55-S58

[121] Pham TN, Bordage S, Pudlo M, Demougeot C, Thai KM, Girard-Thernier C. Cinnamide derivates as mammalian arginase inhibitors: synthesis, biological evaluation and molecular docking. Int J Mol Sci 2016. doi:10.3390/ijms17101656

[122] Pernow ], Kissa A, Tratsiakovich Y, Climent B. Tissue-specific up-regulation of arginase I and II induced by $\mathrm{p} 38$ MAPK mediates endothelial dysfunction in type 1 diabetes mellitus. $\mathrm{Br}$ J Pharmacol 2015; 172: 4684-4698

[123] Cederbaum SD, Yu H, Grody WW, Kern RM, Yoo P, Iyer RK. Arginase I and II: do their functions overlap? Mol Genet Metab 2004; 81: S38-S44

[124] Pudlo M, Demougeot C, Girard-Thernier C. Arginase inhibitors: a rational approach over one century. Med Res Rev 2017; 37: 475-513

[125] Bagnost T, Ma L, da Silva RF, Rezakhaniha R, Houdayer C, Stergiopulos N, André C, Guillaume Y, Berthelot A, Demougeot C. Cardiovascular effects of arginase inhibition in spontaneously hypertensive rats with fully developed hypertension. Cardiovasc Res 2010; 87: 569-577

[126] Wang L, Bhatta A, Toque HA, Rojas M, Yao L, Xu Z, Patel C, Caldwell RB, Caldwell RW. Arginase inhibition enhances angiogenesis in endothelial cells exposed to hypoxia. Microvasc Res 2015; 98: 1-18

[127] Kavalukas SL, Uzgare AR, Bivalacqua TJ, Barbul A. Arginase inhibition promotes wound healing in mice. Surgery 2011. doi:10.1016/j. surg.2011.07.012

[128] Williamson G. The role of polyphenols in modern nutrition. Nutr Bull 2017; 42: 226-235

[129] Santos AC, Costa G, Veiga F, Figueiredo IV, Batista MT, Ribeiro A]. Advance in methods studying the pharmacokinetics of polyphenols. Curr Drug Metab 2014; 15: 96-115

[130] Manach C, Scalbert A, Morand C, Rémésy C, Jiménez L. Polyphenols: food sources and bioavailability. Am J Clin Nutr 2004; 79: 727-747

[131] Chen Z, Zheng S, Li L, Jiang H. Metabolism of flavonoids in human: a comprehensive review. Cur Drug Metab 2014; 15: 48-61

[132] Lodi F, Jimenez R, Moreno L, Kroon PA, Needs PW, Hughes DA, SantosBuelga C, Gonzalez-Paramas A, Cogolludo A, Lopez-Sepulveda R, Duarte J, Perez-Vizcaino F. Glucuronidated and sulfated metabolites of the flavonoid quercetin prevent endothelial dysfunction but lack direct vasorelaxant effects in rat aorta. Atherosclerosis 2009; 204: 34-39 